\title{
LA REESTATIZACIÓN DE UN SERVICIO ESENCIAL EN EL ÁREA METROPOLITANA DE BUENOS AIRES. EL CASO DE LA EMPRESA AGUA Y SANEAMIENTOS ARGENTINOS S.A. (AYSA) (2006-2018)
}

\author{
Mariela V. Rocca ${ }^{(\cdot)}$ \\ Universidad Nacional de La Plata y \\ CEAP/UBA (Argentina)
}

\section{RESUMEN}

Transcurridos más de diez años de la creación de Aguas y Saneamientos Argentinos S.A. (AySA), este trabajo analiza la reestatización del servicio de agua potable y saneamiento del Área Metropolitana de Buenos Aires, a partir de estudiar el desempeño empresario desde 2006. ¿Qué características adoptó la gestión estatal del senvicio? ¿Cómo se compatibilizó el concepto de eficiencia empresarial con el deber de garantizar el acceso a un servicio esencial? Una primera aproximación parece mostrar que la gestión estatal privilegió el mantenimiento y expansión de los servicios por sobre los resultados económicos de la compañía. Considerando el cambio político producido en diciembre de 2015, se abordan también las continuidades y rupturas con el período anterior. El análisis desarrollado se nutre de la integración de datos e información provenientes de documentos, legislación y estadísticas oficiales, informes y balances empresarios, artículos periodísticos y entrevistas semiestructuradas a informantes clave. Mediante este trabajo se procura aportar evidencia empírica sobre cómo funciona la participación estatal empresaria en un servicio esencial.

\section{PALABRAS CLAVE:}

servicio de agua potable y saneamiento, regulación estatal, reestatización, empresa pública.

(•) E-mail: maverocc@yahoo.com.ar

\section{ABSTRACT}

After more than 10 years of the creation of Aguas $y$ Saneamientos Argentinos S.A. (AySA), this article analyzes the re-nationalization of the drinking water and sanitation senvices of the Metropolitan Area of Buenos Aires, based on the study of its performance since 2006. What sort of characteristics did State management adopt? Was the concept of efficiency reconciled with the State duty to guarantee the access to an essential service? The first inquiries seem to show that State management privileged the maintenance and expansion of services over the economic results of the company. Given the change of National Government in December 2015 , the continuities and ruptures with the previous period are also addressed. The analysis is based on official documents, legislation and statistics, company balance sheets and reports, newspaper articles and semi-structured interviews. This article provides empirical evidence on how State ownership works in an essential public utility.

\section{KEY WORDS:}

Drinking water and sanitation services, State regulation, re-nationalisation, State-owned enterprise.

RECEPCIÓN : $15 / 09 / 18$

ACEPTACIÓN FINAL: 26/11/18 


\section{INTRODUCCIÓN}

Aun cuando en las últimas tres décadas del siglo XX se había afianzado la idea de que el Estado no debía intervenir directamente en la economía, desde mediados de los 2000, se ha evidenciado una reversión de este proceso, pudiéndose constatar una mayor presencia de empresas públicas en países desarrollados y en vías de desarrollo. Diversos autores (Warner 2008, Ramesh et al. 2010, Florio, 2013 y 2014; Cló et al. 2015, entre otros) coinciden en señalar que, a partir de la crisis financiera de 2007-2008, los Estados recuperaron un rol más activo en algunos sectores donde habían dejado de participar (bancos, compañías de seguros, servicios públicos, entre otros). En algunos países de América Latina, dicha participación tuvo por objeto contrarrestar las consecuencias derivadas de las reformas neoliberales implementadas y afianzar la soberanía sobre sectores estratégicos que habían sido privatizados. Este resurgir de la intervención estatal no presenta las mismas condiciones del modelo vigente en los años sesenta sino que se trata de un fenómeno más complejo donde se combina el uso de los mercados, la planificación estatal y la participación pública (Warner, 2008). Al respecto, Cló et al. (2015) puntualizan que el mercado en el que las empresas estatales operaban como monopolio se encuentra liberalizado y abierto a la competencia internacional con empresas 
privadas y otras también estatales. Asimismo, de estar reguladas por el derecho público han pasado a estarlo bajo el derecho privado debido a su constitución como sociedades anónimas. Esto último permite que algunas coticen en bolsa y puedan estar parcialmente abiertas al capital privado.

Teniendo en cuenta estos aspectos y puntualizando el análisis en los senicios públicos de infraestructura, debe señalarse que, en paralelo a la desaceleración de las privatizaciones en el sector, se presentaron escenarios de reestatización y remunicipalización de las prestaciones. Principalmente, esto se debió a que las ventajas enunciadas respecto de la mayor eficiencia de las gestión privada resultaron, en muchos casos, limitadas o inexistentes. Algunos de los aspectos más cuestionados se plantearon con respecto a los "(...) excesivos precios cobrados a los usuarios por los concesionarios privados, (...) la sostenibilidad de la inversión, las cuestiones ambientales y la accesibilidad y calidad del servicio" (Florio, 2013: 6, traducción propia). Al respecto de esta tendencia hacia la corporatización, McDonald (2015: 14) señala que la misma "plantea cuestiones contradictorias y complejas sobre el significado de "lo público" y del carácter del Estado en el suministro de servicios esenciales" pues que una empresa sea pública en teoría no necesariamente implica que lo sea en la práctica. Es decir, la corporatización puede adoptar una forma progresista de prestación o constituirse bajo una lógica de mercantilización.

Las empresas corporatizadas neoliberales se comportan como compañías privadas pues se sustentan en su discurso y prácticas. De este modo, los gerentes buscan «incrementar los ingresos fijando precios que reflejen los costos y reduciendo los gastos mediante la externalización y otras formas discretas de recorte de gastos" (McDonald, 2015: 26-27). Los servicios quedan reducidos así a mercancías y los consumidores son identificados más como clientes que como ciudadanos. Asimismo las empresas operan en las zonas más rentables para luego, a partir de esos ingresos, financiar las prestaciones en las más desfavorables. Sin embargo, esto no siempre se concreta adecuadamente. En general, al funcionar de manera aislada sin articular políticas con otras prestaciones estatales, se reducen los alcances de la planificación de los servicios. En cuanto a las formas progresistas posibles, McDonald y Ruiters (2012) proponen una tipología en la que identifican tres tipos institucionales: 1) entidad pública, 2) entidad sin fines de lucro y 3) partenariados, en los que dos más organismos públicos y/o sin fines de lucro suministran el servicio de manera conjunta. Quedan excluidos así los operadores privados y los gubernamentales, no gubernamentales o comunitarios con fines de lucro. "La lógica de esta exclusión estaría en que la búsqueda de lucro es una pieza 
clave de los problemas asociados con la privatización y la comercialización» (McDonald y Ruiters, 2012: 29).

Los servicios de agua potable y saneamiento no fueron una excepción en cuanto al incremento de la participación estatal en la gestión de las prestaciones (Hall y Lobina, 2006). Los problemas presentados en las concesiones privadas (escasas inversiones, tarifas elevadas, baja calidad, prácticas de corrupción, etc.) derivaron principalmente en los ya señalados procesos de reestatización y remunicipalización (Pigeon et al., 2013). Tal como lo analizan Balanyá et al. (2005) y Hachfeld (2008) el rechazo a la prestación privada de los servicios adoptó diversas formas que abarcaron desde la oposición a los intentos de concesión hasta la reversión de las mismas. A modo de ejemplo, en Porto Alegre y Recife (Brasil) mediante el voto popular, las comunidades lograron que los servicios permanecieran en la órbita pública. Existieron también conflictos de mayor envergadura como el levantamiento popular en la ciudad de Cochabamba, Bolivia (abril de 2000) que derivó en el fin de la concesión (Hall y Lobina, 2002). En cuanto a las experiencias en Estados Unidos y Europa, vale destacar para el primero que, aun cuando el $86 \%$ de la población recibe los servicios a través de gobiernos locales u otras entidades públicas, la tendencia hacia la remunicipalización fue incrementándose (Grant, 2015). Respecto de Europa, la proporción que alcanzó este proceso puede dimensionarse a partir del caso francés. Hall et al. (2013) señalan que en Francia, desde el comienzo del nuevo siglo, el número de remunicipalizaciones comenzó a crecer a pesar del predominante rol asignado a las compañías privadas. El caso más emblemático fue la remunicipalización de las prestaciones en París en 2010, pues los servicios eran suministrados por las multinacionales francesas Veolia y Suez, que dominan el mercado global en el sector.

Con orígenes y resultados diversos, las experiencias expuestas evidencian la amplia riqueza analítica presente en estas formas de gestión pública/estatal y fundamentan el estudio del servicio de agua potable y saneamiento del Área Metropolitana de Buenos Aires, que fuera reestatizado por el Estado argentino en marzo de 2006. Este servicio a cargo de la empresa Agua y Saneamientos Argentinos S.A. (AySA), constituye uno de los más importantes de Sudamérica pues cubre una superficie de $3.304 \mathrm{~km}^{2}$, que incluye a la Ciudad Autónoma de Buenos Aires y a 26 partidos del Conurbano Bonaerense (Provincia de Buenos Aires), abarcando una población total de 13.857.216 habitantes. Aun cuando los servicios de agua potable y saneamiento fueran descentralizados a las provincias en $1980^{1}$, el Estado Nacional mantuvo la titularidad sobre esta prestación que territorialmente comprende la totalidad y una parte de dos juris- 
dicciones subnacionales. Dicha condición la distingue por sobre cualquier otro caso de provisión de este servicio en el país. Teniendo en cuenta lo señalado, el artículo se interroga por las características que adoptó la gestión estatal del servicio, a partir de analizar la actuación de la compañía. Considerando el cambio de gobierno producido en diciembre de $2015^{2}$, se abordan también las continuidades y rupturas con el período anterior. La exposición se organiza en tres apartados. En el primero de ellos, se presenta el marco analítico a partir del cual se analizará el caso de AySA. El segundo apartado examina el desempeño empresario buscando semejanzas y diferencias entre períodos gubernamentales. Por último, el tercer apartado está destinado a las reflexiones finales.

\section{2 dE LA CONCESIÓN PRIVADA A LA REESTATIZACIÓN DE LOS SERVICIOS DE AGUA POTABLE Y SANEAMIENTO: HERRAMIENTAS PARA EL ANÁLISIS}

Bajo el supuesto de que las prestadoras públicas eran inherentemente ineficientes, la ola de reformas estructurales impulsada a partir de 1980 promovió ampliamente la transferencia de los servicios públicos al ámbito privado. En lo que refiere al servicio de agua potable y saneamiento, la propuesta neoliberal de fomentar y reintroducir una mayor participación privada se relacionó con la exigencia de reducir el déficit público en el sector e incrementar la eficiencia y calidad del servicio para disminuir los riesgos sanitarios (Lee y Jouravlev, 1997). Sin embargo, en la mayoría de los países donde dichos lineamientos fueron implementados, los resultados obtenidos lejos estuvieron de resolver los problemas que justificaron la transferencia de los sistemas. Tal como señala Castro (2004), la necesidad de extender la cobertura de los servicios mediante una mayor inversión en infraestructura quedó circunscripta al mantenimiento. Muchos operadores obligados contractualmente a efectuar las inversiones, realizaron mejoras en los aspectos comerciales del negocio, donde no se requería un uso intensivo de capital. Este autor agregar que la recurrencia a constantes renegociaciones contractuales terminaron por cancelar o posponer la realización de algunos de los compromisos de inversión establecidos en los contratos originales. Asimismo, frente a la necesidad de reducir la inequidad en el acceso, primó la renuencia empresaria a ampliar la cobertura hacia aquellos sectores que no eran rentables. Por otra parte, los aumentos tarifarios resultantes de las renegociaciones contractuales (justificados en promesas de inversión que finalmente no se concretaban) también afectaron significativamente a las poblaciones más carenciadas. Especialmente, los altos cargos relativos a 
la conexión desalentaban la incorporación de dichos sectores a los servicios. Finalmente, Castro (2004) destaca que aun cuando, retóricamente, la participación ciudadana también fuera proclamada como una cuestión clave para garantizar el éxito de las reformas en el sector, en los hechos, la mayoría de las políticas implementadas propiciaron una intervención limitada o inexistente.

Aunque deben considerarse las características propias de los procesos ocurridos en cada país o región, los límites y problemas derivados de la prestación privada de los servicios concitaron la implementación de cambios en su gestión. Tal como se indicara, se presentaron diversas alternativas entre las que se destacaron aquellas que priorizaron la participación pública o estatal vía reestatizaciones y remunicipalizaciones. Este traspaso concitó el interés de diversos autores por analizar el desempeño de las nuevas prestadoras. Algunos trabajos (Alfaro Fernandois, 2009; Bohoslavsky, 2010; Ferro et al., 2011, Lentini (2011) y Hantke-Domas y Jouravlev, 2014, entre otros) pusieron el foco sobre el criterio de eficiencia, los factores exógenos y endógenos que pueden favorecerla y las posibles formas para efectuar su medición.

«Empresas sanitarias eficientes son aquellas que cumplen a cabalidad sus objetivos, prestando servicios a toda la población del área de su responsabilidad, con la calidad exigida, operando al costo mínimo y cobrando tarifas que correspondan a este costo mínimo y que consideren la remuneración justa a los factores productivos, en términos generales: a los recursos naturales y humanos utilizados y al capital invertido. Estos cuatro requisitos - cobertura máxima, calidad exigida por las normas, operación al mínimo costo y tarifas de autosuficiencia financiera - son inseparables, y ninguno puede ser alcanzado sin la concurrencia de los otros tres" (Alfaro Fernandois, 2009: 23, destacado en el original).

Estos enfoques buscaron rediscutir el alcance del criterio de eficiencia en relación a las características económicas de los servicios y su necesaria complementariedad con el criterio de equidad. Asimismo plantearon nuevos interrogantes sobre el carácter que debía asumir el marco institucional y regulatorio que orientara el desempeño de dichas empresas. Es decir, "si la idea de eficiencia inserta en los marcos normativos existentes (era) suficiente garantía para asegurar que un operador público -en manos municipales o estatalesse (comportase) de tal manera o más bien se (requieran) enfoques y controles complementarios o diferentes" (Hantke-Domas y Jouravlev, 2014: 16). 
Si bien paralelamente a los niveles de eficiencia comercial, estas miradas, añaden el cumplimiento de fines sociales como una de las variables a considerar respecto del desempeño de la empresa sanitaria (Bohoslavsky, 2010), otro grupo de autores (McDonald y Ruiters, 2012; Kishimoto et al., 2015 y McDonald, 2015, entre otros) enfatizan en sus análisis el abordaje de esos últimos aspectos. Dichos autores, procuran avanzar en la discusión de nuevos indicadores que permitan evaluar costos y beneficios surgidos de las obligaciones no comerciales que asumen las prestadoras. En este sentido, McDonald y Ruiters (2012) proponen diversos

"(...) criterios (que) pretenden ser un primer intento de proporcionar comparaciones generales de los éxitos/fracasos de diferentes alternativas, así como iniciativas de mejora y reforma en la prestación de servicios públicos. (...) (En) ningún caso pretenden ser una evaluación exhaustiva (...) partiendo de la base de que (...) ninguna entidad de servicio podía cumplir con todos los criterios y que era muy posible que surgieran tensiones significativas entre las categorías (por ejemplo, una mayor eficiencia a expensas de recortar puestos de trabajo)" (McDonald y Ruiters, 2012: 31-32).

De este modo, junto a los criterios de eficiencia económica y equidad, incorporan y desarrollan los conceptos de participación, calidad del servicio, rendición de cuentas, transparencia, calidad del lugar de trabajo, sostenibilidad, solidaridad, ética pública y transferibilidad.

Respecto del criterio de eficiencia económica, ponen en discusión algunos aspectos. Entre éstos señalan la necesidad de tener en cuenta un horizonte de análisis prolongado en el tiempo porque muchos resultados se deben a inversiones a largo plazo en personal y equipamiento que no serían contempladas en la evaluación de corto alcance. Por otro lado, este criterio puede colisionar con otros, pues "puede alcanzarse a expensas de la salud, la seguridad y las condiciones laborales de los trabajadores o de la participación comunitaria" (McDonald y Ruiters, 2012: 40). Plantean así que hay aspectos relacionados con los objetivos sociales de la prestación que quedan por fuera de este tipo de abordaje y que sería mucho más apropiado considerar a pesar de la dificultad de su medición. En cuanto a la equidad plantean que no constituye un concepto fácil de medir. Por una parte, es vinculada a la disponibilidad física de los servicios para diversos grupos sociales, es decir, de qué modo son distribuidos de acuerdo con las necesidades de estos sectores o si se establece un conjunto de prestaciones básicas que deben ser cubiertas para todos. Otros enfoques se 
centralizan en la accesibilidad, con lo que se contempla la cantidad y calidad de las prestaciones. El sistema de fijación de la tarifa también es considerado un factor importante para determinar el nivel de equidad con que se brindan los servicios. Finalmente, puntualizan que, más allá de que en la práctica se apliquen criterios de equidad, es necesario que se establezcan compromisos formales o institucionales a fin de garantizar su aplicación de manera sistemática.

En relación al criterio de participación, los autores plantean que se requiere cierta precisión en su definición pues es referido tanto en la literatura a favor como crítica de la privatización de los servicios. Debe contemplarse que la participación sea significativa y no se limite a una mera consulta, que los ciudadanos tengan poder para generar cambios de importancia respecto de la gestión de los servicios. Asimismo se plantea que exista una participación equitativa de los miembros que integran la comunidad por lo que se pone en cuestión el grado de representatividad de los participantes respecto de las partes interesadas y de qué modo se incluyen, si es que se hace, a sectores posiblemente marginados. Es necesario también que se cuente con recursos técnicos, humanos y económicos junto a información adecuada y una formación específica para que la intervención pueda ser lo más informada posible. El éxito de la participación también depende del grado de institucionalización y de que su propia constitución le permita adaptarse a nuevas situaciones que puedan surgir en la práctica.

La calidad del servicio también se presenta como un criterio problemático debido a que depende mucho de upercepciones culturales y demandas del mercado" y ha quedado asociado a una cualidad que puede cumplimentar mejor el sector privado respecto del público. En lo relativo a la rendición de cuentas agregan que no sólo debiera contemplarse su cumplimiento sino cuál es su alcance, es decir, quiénes deben rendir cuentas y ante quiénes y si los mecanismos establecidos efectivamente se ejecutan. De este modo, plantean un control tanto vertical como horizontal en el que los ciudadanos participen activamente. Vinculado a esto, se encuentra el criterio de transparencia pues el ejercicio de control requiere del acceso a la información sobre el funcionamiento y el desempeño económico del servicio. Entre los criterios a considerar incluyen también la calidad del lugar trabajo, pues entienden que los trabajadores son fundamentales para garantizar las prestaciones. Enfatizan así la necesidad de que éstos cuenten con salarios y condiciones laborales apropiadas que les permitan desarrollarse profesionalmente.

En lo referente a la sostenibilidad de los servicios, McDonald y Ruiters (2012) aluden a los debates en relación a cómo asegurar la obtención de los recursos 
económicos y medioambientales adecuados para que ésta sea posible. Puntualizan que algunos autores abogan por que exista autonomía e independencia del Estado para la obtención de los recursos, mientras otros, por el contrario, plantean la necesidad de su involucramiento para lograr el éxito de las empresas públicas cuando no están directamente a su cargo. Asimismo, respecto de los recursos medioambientales, señalan que en su producción y consumo se debe evitar una explotación excesiva que ponga en peligro su obtención y calidad. Evaluar el nivel de solidaridad presente en las prestaciones se relaciona con la creación de vínculos e intercambios entre los diversos sectores de la sociedad y los proveedores del servicio. Aun cuando esta solidaridad puede traducirse de diversas maneras, el objetivo es comprender el modo en que contribuye a "superar los efectos individualizadores y enajenantes de la comercialización" (McDonald y Ruiters, 2012: 47).

Dado que el criterio de ética pública constituye uno de los principios destacados que motivan los modelos públicos de senvicios, los autores señalan la necesidad de avanzar en una definición explícita que permita dar cuenta de todos los aspectos considerados. Destacan así algunas interpretaciones amplias de lo público que se extienden más allá de la titularidad formal de la gestión y que contemplan de qué manera ese carácter público atraviesa al conjunto de actores que integran el sistema: "sentir orgullo del propio trabajo (trabajadores), valorar al personal (administradores y usuarios), transparencia y rendición de cuentas (encargados de políticas) y participación comunitaria” (McDonald y Ruiters, 2012: 47). Finalmente, del criterio de transferibilidad señalan que si bien no constituye un indicador de éxito, tener en consideración factores como la ubicación geográfica, el tamaño de la población, el clima político, entre otros, que permitan analizar la adaptabilidad/pertinencia de ciertos modelos de gestión en determinados contextos es de utilidad por las enseñanzas que pueden obtenerse para la constitución de nuevos servicios.

En el apartado que sigue, se analizará la gestión de AySA, considerando aquellos criterios que sean posibles de identificar de acuerdo con los datos disponibles. Si bien dichos indicadores pueden presentar aspectos susceptibles de discusión, éstos serán problematizados a la luz de las particularidades del caso. La elección de este enfoque tiene por objeto avanzar en una caracterización amplia donde se contemplen aspectos comerciales y no comerciales del servicio. Asimismo se tendrá en cuenta el cambio implementado en la orientación de la política hacia los servicios públicos a partir de diciembre de 2015. 


\section{DESEMPEÑO de AGUA Y SANEAMIENTOS ARGENTINOS S.A.}

Desde el inicio de la renegociación contractual posconvertibilidad ${ }^{3}$, la operadora privada, Aguas Argentinas S.A. (AASA) había planteado un elevado nivel de exigencias al Estado que poco se correspondió con su desempeño ${ }^{4}$. Al vislumbrar que no sería posible recomponer las condiciones pasadas, AASA optó por no continuar con la prestación $n^{5}$. Frente a esta decisión empresaria, el Poder Ejecutivo Nacional (PEN) trató de evitar que esta salida fuera considerada un fracaso en la renegociación. Alegando la necesidad de proteger la salud de los usuarios a causa de irregularidades en materia de nitratos y cobertura, decidió rescindirle el contrato por culpa del concesionario (Decreto $N^{\circ} 303 / 06$, 22/03/06). Asimismo mediante el Decreto N ${ }^{\circ} 304 / 06$ y su ratificación a través de la Ley No 26.100 (07/06/06), se creó la empresa estatal, AySA. El 90\% de las acciones quedó a cargo del Estado, bajo la titularidad del Ministerio de Planificación Federal, Inversión Pública y Senvicios (MPLAN) y el 10\% restante en poder de los trabajadores adheridos al Programa de Propiedad Participada (PPP). La nueva prestataria mantuvo el esquema empresario de su antecesora pues no se dispuso ningún tipo de subdivisión de la compañía. Conservó también los activos de la concesión anterior e incorporó automáticamente a su planta a los trabajadores de AASA. En el organigrama funcional se dispuso que su desenvolvimiento y la aprobación de su plan de acción y presupuesto fueran supervisados por el MPLAN.

Al abordar su desempeño empresario puede señalarse que para el período 2006-2015, los datos económicos financieros ${ }^{6}$ mostraron que sólo durante $2008^{7}$ y 2009 las transferencias corrientes recibidas por la empresa estatal representaron un porcentaje menor en el total de sus ingresos corrientes. En el Gráfico 1 se muestra la composición de dichos ingresos a partir de distinguir las transferencias y los ingresos de operación. Aun cuando en los años posteriores, dichas transferencias constituyeron, en promedio, un $61 \%$ de sus ingresos, no llegaron a cubrir el total de sus gastos por lo que se registraron resultados económicos negativos (Gráfico 2). Respecto de la composición de los gastos de operación, las erogaciones relativas al personal y aquellas efectuadas en bienes y servicios, presentaron valores constantes para toda la serie. En promedio, las primeras representaron el $46 \%$ del total de estos gastos, mientras que las segundas un 51\%. En cuanto a las transferencias de capital, éstas fueron en constante ascenso hasta 2012 por lo que la mayoría de las obras fueron efectuadas principalmente con aportes del Estado Nacional (Gráfico 3). El monto registrado a diciembre de 2015 representó un valor treinta y cinco veces mayor que el establecido al inicio de la gestión pública. Tal como se 
presenta en el Gráfico 4, la relación ingresos/gastos de capital presentó valores positivos sólo durante los primeros tres años de la serie.

Al analizar estos aspectos a partir del cambio de gobierno a fines de 2015, se observaron algunas continuidades y también rupturas. En relación a las transferencias corrientes, se revirtió la tendencia de los seis años anteriores pues la empresa recibió bajo ese concepto un valor semejante (38\%) al registrado en los dos primeros años de la serie, llegando, en 2017, a no registrar transferencias bajo ese concepto. Aun cuando en 2016 se presentó un resultado económico positivo, cuestión que no se registraba desde 2008, en 2017 nuevamente fue negativo. El incremento de la participación de los ingresos de operación frente a las transferencias corrientes y el resultado económico positivo en 2016 pueden ser explicados por el aumento de tarifas dispuesto a partir del $1^{\circ}$ de abril de ese mismo año $0^{8}$. Por el contrario, los gastos de operación no presentaron mayores diferencias respecto de los valores que se venían registrando. Si bien en 2016 y 2017, las erogaciones relativas al personal descendieron dos puntos porcentuales en relación a diciembre de 2015 (de representar el 48\% pasaron al 46\%), el valor registrado fue el mismo que en 2014. Con respecto a los gastos en bienes y servicios se mantuvo también el porcentaje de aquel año (49\% para 2016 y 48\% para 2017). En lo que refiere a las transferencias de capital, éstas mostraron para 2016 $\underline{121}$ un aumento del $35 \%$ respecto de diciembre de 2015 . Al comparar el monto transferido en 2017 con el de 2016 se presentó un descenso del 6\%. Estos datos evidencian el rol clave que posee el Estado Nacional como garante de las inversiones en el sector. 


\section{Gráfico 1.}

Transferencias corrientes e ingresos de operación AySA (2006-2017)

(en miles de pesos, a valores constantes**)

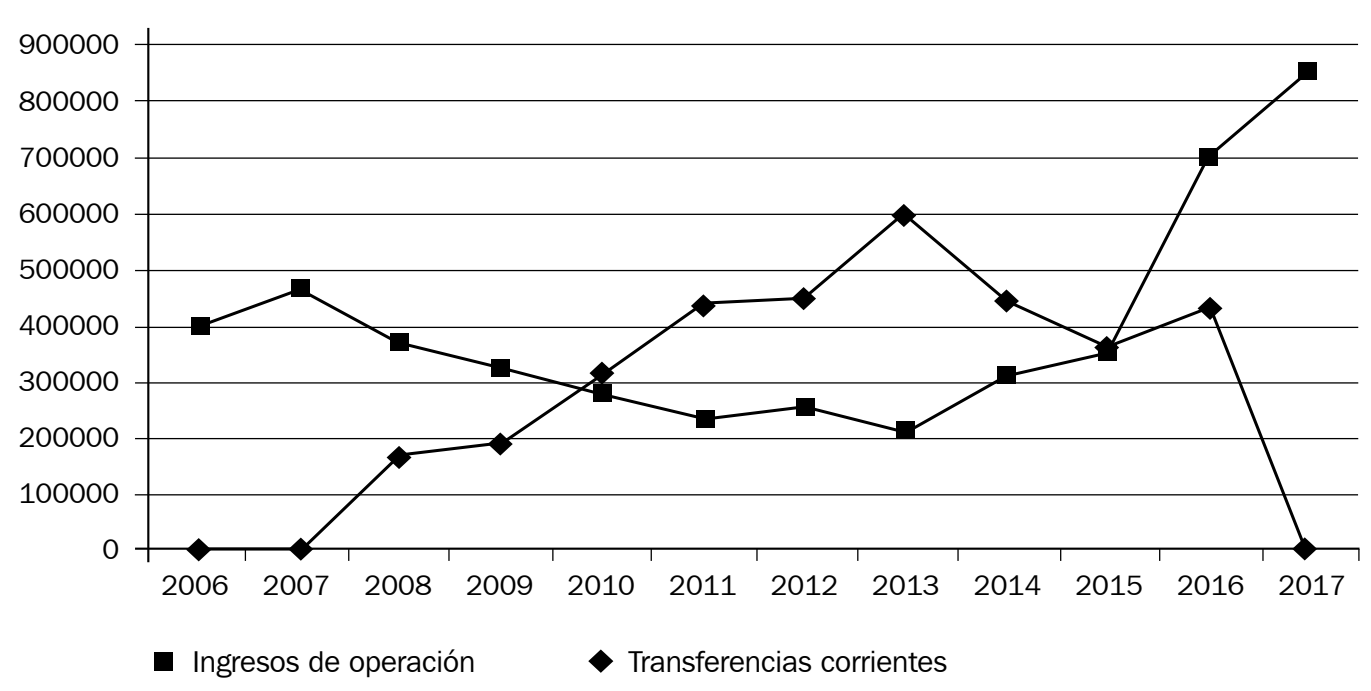

$* *$ IPI base $2004=100$.

Fuente: elaboración propia en base a Ejecución presupuestaria AySA (2006-2017).

\section{Gráfico 2.}

Ingresos/gastos corrientes y resultado económico AySA (2006-2017)

(en miles de pesos, a valores constantes*)

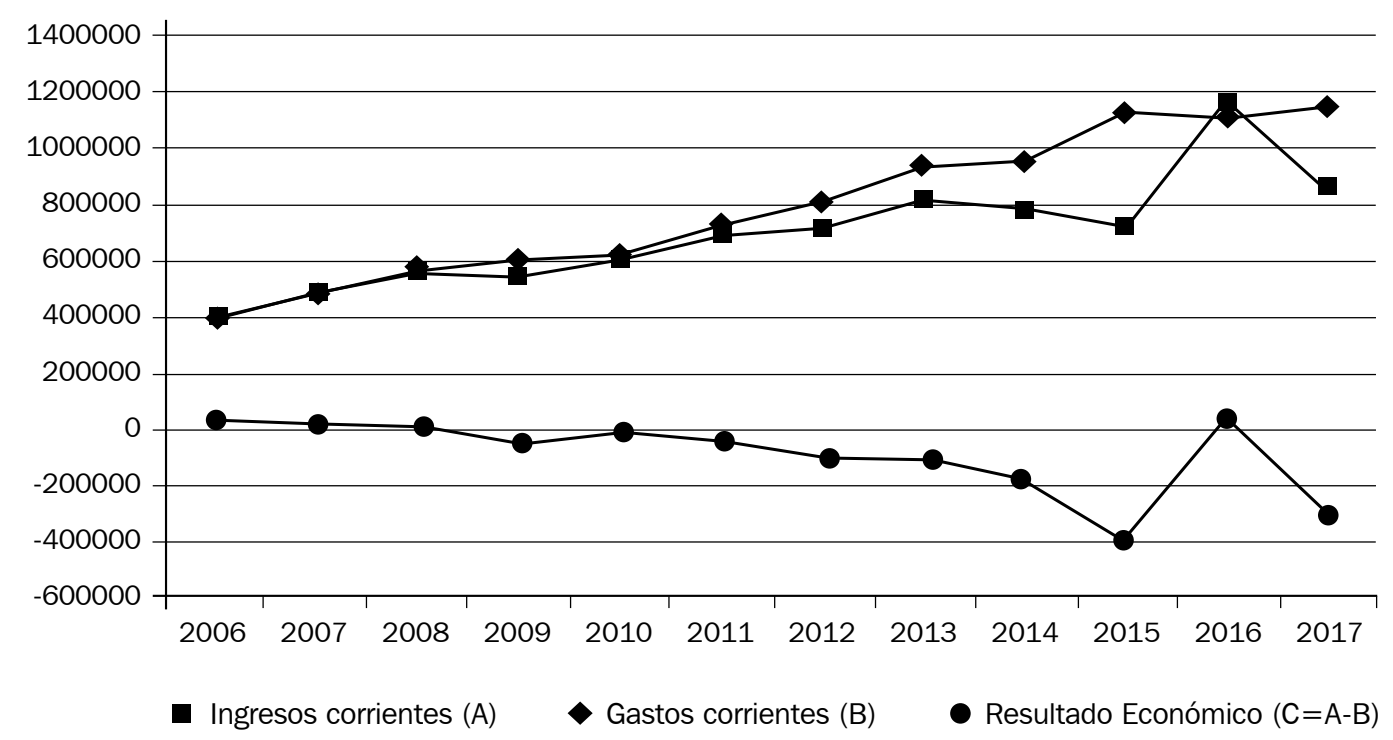

*IPI base $2004=100$.

Fuente: elaboración propia en base a Ejecución presupuestaria AySA (2006-2017). 


\section{Gráfico 3.}

Ingresos de capital AySA: recursos propios y transferencias de capital (2006-2017) (en miles de pesos, a valores constantes*)

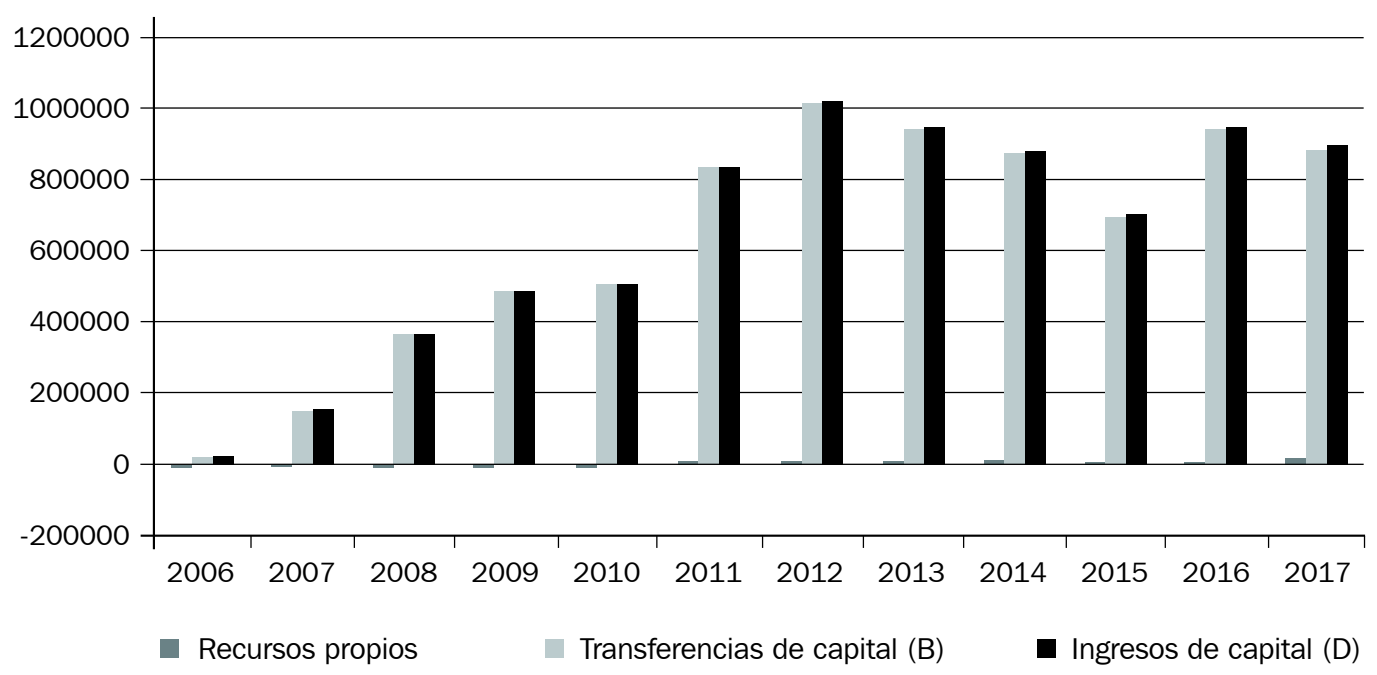

*IPI base $2004=100$.

Fuente: elaboración propia en base a Ejecución presupuestaria AySA (2006-2017).

\section{Gráfico 4.}

Ingresos/gastos de capital y resultado económico AySA (2006-2017)

(en miles de pesos, a valores constantes*)

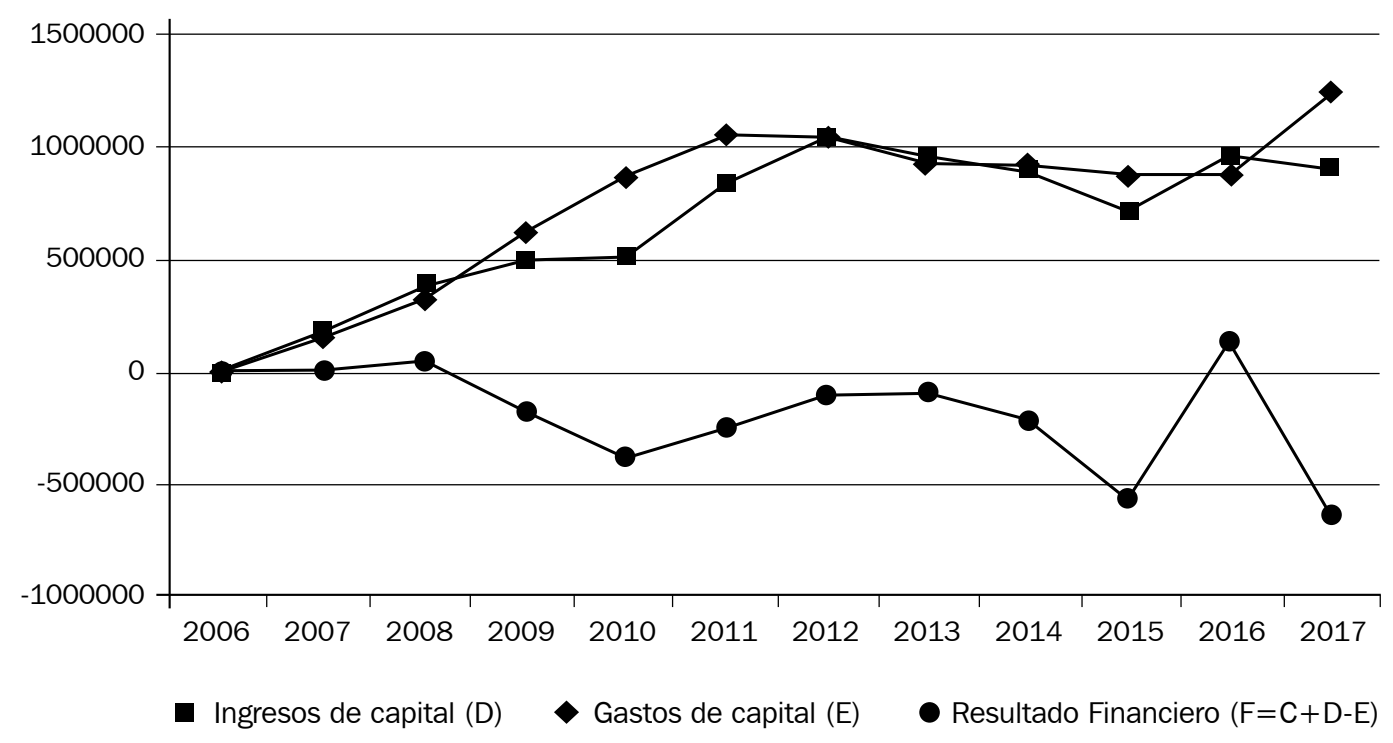

$*$ IPI base $2004=100$.

Fuente: elaboración propia en base a Ejecución presupuestaria AySA (2006-2017). 
En lo que refiere al nivel de endeudamiento sobre el patrimonio neto (Gráfico 5), éste presentó una tendencia oscilante aunque predominantemente descendente a lo largo del período 2006-2016, de 118\% en 2006 pasó al 32\% en 2016. La rentabilidad empresaria (Gráfico 6) también registró una tendencia decreciente, presentando valores negativos a partir de 2009 (con excepción del año 2016). Estos datos se inscriben en el marco ya descripto respecto del aporte constante y en aumento de transferencias del Tesoro producto de la falta de recursos propios suficientes para cubrir su operatoria. Para 2016 este cambio de tendencia se vincula al incremento tarifario ya mencionado.

\section{Gráfico 5.}

Nivel de endeudamiento sobre patrimonio neto AySA (2006-2016) (en porcentaje)

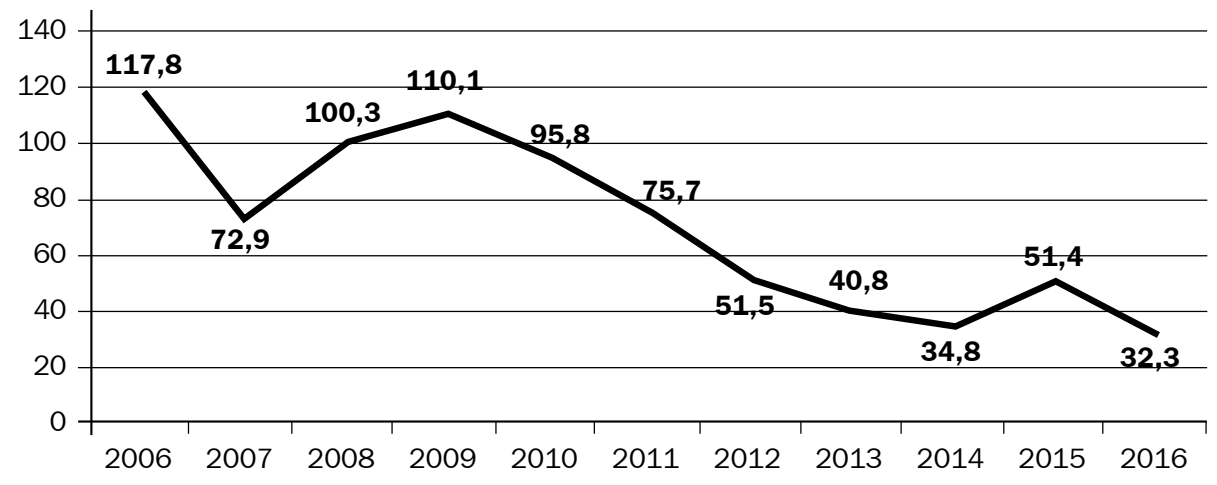

Fuente: elaboración propia en base a Informes Anuales de AySA (2006-2016). 


\section{Gráfico 6.}

Rentabilidad sobre patrimonio neto AySA (2006-2016) (en porcentaje)

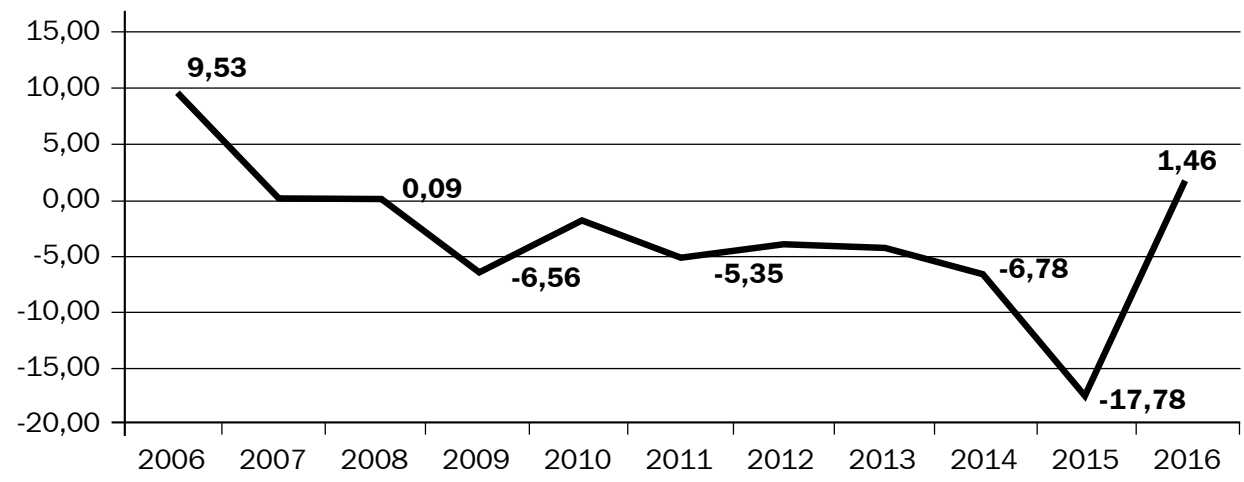

Fuente: elaboración propia en base a Informes Anuales de AySA (2006-2016).

Considerando el criterio de eficiencia económica clásico, el déficit de AySA puede ser cuestionado ya que, con excepción de unos pocos años, no logró cubrir con ingresos propios ni sus gastos corrientes ni los de capital. Sin embargo, tal como señalan Mc Donald y Ruiters (2012), dicho criterio deja por fuera otros aspectos relativos a los objetivos sociales involucrados en el servicio. Los datos consignados permitieron mostrar que, para el período 2006-2015, el objetivo de gestión no estuvo asociado a la búsqueda de rentabilidad sino a garantizar el servicio a pesar del desequilibrio en los resultados económicosfinancieros de la empresa. Esta decisión debe ser analizada en el marco de las medidas generales tomadas en materia de servicios públicos (inversión estatal en infraestructura, congelamiento y posterior aumento gradual de las tarifas, el incremento de los subsidios, etc.) con las que, a la vez que se buscó ampliar la cobertura, se procuró evitar impactos directos sobre la inflación ${ }^{9}$. A partir de 2016, con una nueva orientación de política que retiró al Estado como principal promotor del acceso a los servicios públicos, esta lógica presentó cambios pues la sostenibilidad de la prestación quedó vinculada a los incrementos tarifarios.

Si para abordar el criterio de equidad se analiza la cuestión tarifaria, caben identificar tres etapas: 1) desde el inicio de la reestatización en marzo de 2006 hasta noviembre de 2011, 2) a partir de diciembre de 2011 hasta marzo de 2016 y 3) desde abril de 2016 en adelante (Cuadro 1). La primera de ellas se caracterizó por el mantenimiento de gran parte de las condiciones vigentes 
durante la gestión privada. Por un lado, la tarifa permaneció congelada al valor de enero de $2002^{10}$. Esta decisión se enmarcó en una política más general mediante la cual, el PEN evitó trasladar a los consumidores residenciales el impacto de los aumentos de los servicios públicos. Así buscó contener una posible alza en el índice inflacionario y resguardar el poder adquisitivo de los sectores de más bajos recursos. Ligada a esta cuestión fue que se implementó una política de subsidios indirectos cuyos montos fueron incrementándose significativamente y de la que, como ya se señalara, el servicio de agua potable y saneamiento no fue una excepción ${ }^{11}$.

Por otro lado, hasta que las facturas fueron emitidas de acuerdo a lo estipulado por el Reglamento de Aplicación de Normas Tarifarias (RANT) ${ }^{12}$, se mantuvo el régimen tarifario heredado de AASA. Éste se basaba, por una parte, en el sistema de tipo catastral de Obras Sanitarias de la Nación (OSN) y por otra, en un sistema medido, optativo para usuarios residenciales, y obligatorio para los no residenciales ${ }^{13}$ y la venta de agua «en bloque $»^{14}$. De este modo, la tarifa básica bimestral (TBB) se calculaba considerando: el coeficiente de modificación tarifaria "K", el coeficiente zonal "Z", la tarifa general por los servicios suministrados "TG", la superficie cubierta "SC", el coeficiente de edificación "E" sumado a un décimo de la superficie total del terreno "ST». A la vez, la TBB poseía un valor base predeterminado de acuerdo al tipo de usuario (Tarifa Básica Bimestral Mínima) ${ }^{15}$. A esta tarifa mínima se le sumaba un 2,67\% para financiar al Ente regulador ${ }^{16}$ y la alícuota del Impuesto al Valor Agregado (IVA). En relación al régimen de cobro de servicios medidos, se trató de un sistema mixto pues relacionaba la superficie y características edilicias con el consumo real. «(Abonan) en concepto de cargo fijo un monto mínimo equivalente al $50 \%$ de la cuota fija (Tasa Básica Bimestral). A ese valor se adicionan los metros cúbicos consumidos que sobrepasan el consumo bimestral libre para cada categoría o clase de usuarion (García, 1998: 75). Los diferentes cargos fijos (Servicio universal y medio ambiente: SUMA, Cargo de infraestructura, por titularidad no declarada y por mantenimiento al senvicio) que habían sido incorporados a la tarifa durante la concesión a AASA y que influyeron en su incremento real ${ }^{17}$ tampoco sufrieron modificaciones ${ }^{18}$. De este modo, el cambio de gestión no conllevó la rediscusión de su carácter regresivo ${ }^{19}$. Para la serie 2006-2017 estos cargos fijos representaron, en promedio, el 18\% del total de los ingresos de AySA en concepto de facturación.

El segundo período que abarca desde diciembre de 2011 hasta marzo de 2016 se caracterizó por progresivos aumentos del coeficiente de modificación tarifaria K y la segmentación de los subsidios. Se buscó así que los incrementos tuvieran un impacto gradual y acorde al poder adquisitivo de los usuarios. 
A través de la Disposición SSRH No 44/11 (02/12/11) se estableció que, a partir del $1^{\circ}$ de diciembre de 2011, el valor del Coeficiente K sería de 3,7331. Esta variación representó un incremento del $290 \%$ que se aplicaría sólo a 169.671 usuarios a quienes se les retiraron los subsidios. El resto tendría un descuento del 74,36\%, por lo que conservarían la tarifa (Aysa, 2017). La primera quita se efectúo a los sectores económicos más rentables (bancos, financieras, juegos de azar, aeropuertos internacionales, empresas de telefonía móvil, hidrocarburos y minería) ${ }^{20}$. A partir de enero de 2012 ésta se extendió a la totalidad de los usuarios de los barrios de mayor valor catastral según la tasa de Alumbrado Barrido y Limpieza (ABL) (Barrio Parque y Puerto Madero) y a los barrios privados. Asimismo se implementó la posibilidad de renunciar voluntariamente a los subsidios (Disposición conjunta № 229/11 y 810/11, $02 / 12 / 11)^{21}$. Continuando con las readecuaciones tarifarias, se dispuso a partir del $1^{\circ}$ de abril de 2014 un nuevo valor para el Coeficiente K: 5,1138 y tres niveles de descuentos de acuerdo a los Coeficientes Zonales que iban decreciendo desde abril hasta agosto (Disposición SSRH № 4/14, 07/04/14). El aumento total fue del $271 \%$ para los usuarios del zonal alto, del $178 \%$ para los del zonal medio y del 95\% para los bajos (Aysa, 2017).

La última etapa que se inició a partir de abril de 2016, mostró un cambio significativo respecto de la política tarifaria. El nuevo gobierno dispuso la eliminación de la mayoría de los subsidios ${ }^{22}$ aunque mantuvo la tarifa social ${ }^{23}$. Con la Disposición SSRH № 62/16 (01/04/16), el Coeficiente K pasó a 16,1937 y se dejaron sin efecto los descuentos para los usuarios de los zonales altos y medios, mientras que para los del zonal bajo la reducción pasó a ser del $25 \%$. Los aumentos experimentados por los primeros fueron del $233 \%$ y $322 \%$ respectivamente y del $375 \%$ para los últimos (Aysa, 2017). Tras la realización de la audiencia pública el 6 de abril de 2017, la tarifa volvió a incrementarse. Aunque se mantuvo el descuento del $25 \%$ para los usuarios residenciales del zonal bajo y la posibilidad de optar por la tarifa social, se fijó un aumento del $23 \%$ para el Coeficiente K $(19,9183)$ (Disposición SSRH № 19-E/17, 02/05/17). Asimismo, a partir del $1^{\circ}$ de noviembre de 2017 , el cargo fijo dejó de incluir factores relativos al inmueble y pasó a constituir una cifra fija bimestral de AR $\$$ $87+$ impuestos por cada servicio (agua y cloaca).

"Las adecuaciones de nivel tarifario que se fueron sucediendo en este proceso, afectaron de manera dispar a distintos segmentos de usuarios, así la combinación de recomposición tarifaria y la eliminación de los descuentos implicó que los mayores impactos durante 2017 se dieran en las áreas de coeficiente zonal 
bajo, y en menor medida en las áreas con coeficiente zonal medio y alto, las que presentaban un atraso tarifario relativo de menor cuantía» (AySA, 2018: 6).

Para 2018, el aumento tarifario dispuesto (Resolución SlyPH № 07/18, 27/04/18) se fundamentó principalmente en dos cuestiones: a) la no aplicación de los cuadros tarifarios vigentes en el Partido de La Matanza ${ }^{24}$ y la ampliación del área concesionada ${ }^{25}$.

"Las medidas que se propician requieren un incremento del nivel tarifario general (ajuste del coeficiente de modificación «K») de la Empresa y una readecuación del esquema de eliminación de los descuentos tarifarios previstos en la Disposición SSRH №19-E/17, para contrarrestar los efectos de la inflación que afecta los costos y para afrontar los déficit operativos derivados de la incorporación de los nuevos partidos al área concesionada" (AySA, 2018: 11).

El Coeficiente K se estableció en 25,0971, representando un incremento del $26 \%$ de las tarifas. Los descuentos para los usuarios del zonal bajo irán descendiendo del $25 \%$ al $6,25 \%$, valor que regirá desde el $1^{\circ}$ de noviembre hasta el 31 de diciembre de 2018.

Respecto del Programa de Tarifa Social, se mantuvieron, hasta 2014, las condiciones vigentes durante la gestión privada ${ }^{26}$. En ese año con la Disposición SSRH No 16/14 (5/09/14) se estableció un nuevo Reglamento del Programa de Tarifa Social y se aprobaron también los Criterios de inclusión y asignación ${ }^{27}$ del beneficio del Programa (Resolución ERAS № 46/14, 27/11/14). Resulta preciso señalar que se contemplaron tres tipos de modalidades de inclusión: a) tarifa social (usuarios residenciales), b) caso social (usuarios residenciales y no residenciales) ${ }^{28}$ y c) tarifa comunitaria (usuarios no residenciales). Las dos primeras toman como unidad de análisis a los hogares, mientras que la última considera a las organizaciones de la sociedad civil. A su vez, bajo el Programa es posible asignar tres tipos de beneficios para cada una de estas modalidades: 1) al acceso al servicio, para aquellos usuarios que no se encuentran conectados a los servicios, 2) al uso del servicio, cuando no pueden afrontar total o parcialmente su pago y 3 ) a la regularización de deudas, para facilitar su cancelación de acuerdo a sus posibilidades económicas. Respecto de los criterios de asignación, mediante la tarifa social y la comunitaria se establecen pautas de descuento del costo de la tarifa, mientras que en la modalidad caso social, el subsidio exime totalmente de pago al usuario. A continuación, en el Cuadro 2 se resumen estos aspectos. 


\section{Cuadro 1.}

Normativa, valor del coeficiente K y subsidios

\begin{tabular}{|c|c|c|c|c|c|}
\hline Normativa & $\begin{array}{l}\text { Disposición } \\
\text { SSRH } \\
\text { N44/2011 }\end{array}$ & $\begin{array}{l}\text { Disposición } \\
\text { SSRH } \\
\text { N } 4 / 2014\end{array}$ & $\begin{array}{l}\text { Disposición } \\
\text { SSRH } \\
\text { N 62/2016 }\end{array}$ & $\begin{array}{l}\text { Disposición } \\
\text { SSRH } \\
N^{\circ} 19-E / 2017\end{array}$ & $\begin{array}{l}\text { Resolución } \\
\text { SlyPH } \\
\text { N }^{\circ} 7 / 2018\end{array}$ \\
\hline $\begin{array}{l}\text { Fecha de } \\
\text { vigencia }\end{array}$ & $\begin{array}{l}\text { a partir del } \\
1^{\circ} \text { de diciembre } \\
\text { de } 2011\end{array}$ & $\begin{array}{l}\text { a partir del } \\
1^{\circ} \text { de abril } \\
\text { de } 2014\end{array}$ & $\begin{array}{l}\text { a partir del } \\
1^{\circ} \text { de abril } \\
\text { de } 2016\end{array}$ & $\begin{array}{l}\text { a partir del } \\
2 \text { de mayo } \\
\text { de } 2017\end{array}$ & $\begin{array}{l}\text { a partir del } \\
1^{\circ} \text { de mayo } \\
\text { de } 2018\end{array}$ \\
\hline Coefic. K & 3,7331 & 5,1138 & 16,1937 & 19,9183 & 25,0971 \\
\hline $\begin{array}{l}\text { Descuen- } \\
\text { tos a } \\
\text { usuarios } \\
\text { residen- } \\
\text { ciales }\end{array}$ & $\begin{array}{l}\text { Usuarios subsi- } \\
\text { diados por el } \\
\text { Estado Nacional. } \\
\text { Reducción del } \\
\text { 74,36\%. }\end{array}$ & $\begin{array}{l}\text { Tres niveles de des- } \\
\text { cuentos de acuerdo } \\
\text { a los Coeficientes } \\
\text { Zonales. Iban } \\
\text { decreciendo hasta } \\
\text { agosto de } 2014 \text {. }\end{array}$ & $\begin{array}{l}\text { Reducción del } 25 \% \\
\text { para usuarios en } \\
\text { áreas de Coefi- } \\
\text { cientes Zonales } \\
\text { bajos (1,45; } 1,30 \\
\text { y 1,10). }\end{array}$ & $\begin{array}{l}\text { Reducción del } 25 \% \\
\text { para usuarios en } \\
\text { áreas de Coefi- } \\
\text { cientes Zonales } \\
\text { bajos }(1,45 ; 1,30 \\
\text { y } 1,10) .\end{array}$ & $\begin{array}{l}\text { Reducción del } 25 \% \\
\text { hasta el } 6,25 \% \\
\text { para usuarios en } \\
\text { áreas de Coefi- } \\
\text { cientes Zonales } \\
\text { bajos (1,45; } 1,30 \\
\text { y } 1,10) .\end{array}$ \\
\hline
\end{tabular}

Fuente: elaboración propia en base a Disposiciones de la Subsecretaría de Recursos Hídricos y Resolución de la Secretaría de Infraestructura y Política Hídrica.

\section{Cuadro 2.}

Programa de tarifa social: principales características

\begin{tabular}{|c|c|c|c|}
\hline Modalidades de inclusión & Unidad de análisis & Criterios de asignación & Tipos de beneficios \\
\hline $\begin{array}{l}\text { Tarifa social } \\
\text { (usuarios residenciales) }\end{array}$ & \multirow[b]{2}{*}{ hogares } & \multirow{3}{*}{$\begin{array}{l}\text { - al acceso al servicio } \\
\text { - al uso del servicio } \\
\text { - a la regularización } \\
\text { de deudas }\end{array}$} & pautas de descuento \\
\hline $\begin{array}{l}\text { Caso social } \\
\text { (usuarios residenciales } \\
\text { y no residenciales) }\end{array}$ & & & eximición de pago \\
\hline $\begin{array}{l}\text { Tarifa comunitaria } \\
\text { (usuarios no residenciales) }\end{array}$ & $\begin{array}{l}\text { organizaciones de } \\
\text { la sociedad civil }\end{array}$ & & pautas de descuento \\
\hline
\end{tabular}

Fuente: elaboración propia en base al Reglamento del Programa de Tarifa Social y los Criterios de inclusión y asignación del beneficio del Programa. 
Producido el traspaso de gobierno, con la Resolución ERAS № 19/16 (26/05/16) se estableció el procedimiento de regularización de deudas en sus diferentes modalidades (Art. $1^{\circ}$ ), se implementó un formulario en línea para tramitar la incorporación de usuarios a la tarifa social ${ }^{29}$ y se renovaron también los Criterios de inclusión y asignación. A este respecto, se elevó el porcentaje de los gastos en servicios optativos a ser considerado para la asignación de los descuentos ${ }^{30}$ (la primera categoría «hasta el $3 \%$ » pasó al $5 \%$; la segunda "del $3 \%$ al $6 \%$ " quedó establecida en "del $5 \%$ al 10\%" y finalmente, "desde el $6 \%$ " cambió a «desde el 10\%») 31. Seguidamente, otra Resolución (ERAS №30/16, 25/07/16) dispuso un nuevo Reglamento y añadió los Criterios previamente establecidos. Aun cuando existieron algunos cambios de forma, la modificación a destacarse se vinculó con la incorporación de los beneficiarios de la "Tarifa Comunitaria (...) bajo la aplicación de una Tarifa General Diaria Fija del Cargo Fijo (TGDF) que corresponde a la categoría de usuario residencial, sin que ello implique no considerarlos a los demás efectos como usuarios no residenciales".

En julio de 2017 (Resolución ERAS № 61/17, 28/07/17), se dispuso para esa modalidad la aplicación, en concepto de beneficio al uso, de un descuento del $25 \%$ sobre la TGDF para el régimen de cobro no medido y del 30\% para el medido. Por último, se sumó una cláusula transitoria en la cual se dispuso la aplicación del subsidio del 25\% para los usuarios de los zonales bajos sin perjuicio de poder solicitar la aplicación de los beneficios del Programa de Tarifa Social. Si se consideran los datos para el período 2006-2015, el promedio de recursos asignados al Programa de Tarifa Social rondó los AR $\$ 4$ millones (a precios corrientes). En cuanto a la evolución de la cantidad de beneficiarios (se incluyen todas las modalidades) ésta fue fluctuante. En 2007 se presentó el valor más alto de la serie con 118.953 beneficiarios, mientras que el registro más bajo fue en 2015 con 15.390. El año 2016 presentó valores muy superiores a los previamente registrados: 253.576 beneficiarios y alrededor de AR $\$$ 115 millones asignados. Estos valores también crecieron en 2017 cuando la cantidad de beneficiarios pasó a ser de 272.328 y el monto destinado AR $\$ 292$ millones (Informes Anuales AySA, 2006-2017). Esta ampliación de la cobertura se vinculó directamente con los incrementos descriptos en materia tarifaria.

"Estos cambios fueron acompañados con un fuerte desarrollo de la Tarifa Social focalizada (...) lo que evidencia un cambio sustancial en la lógica de aplicación de subsidios, avanzando hacia un sistema que focaliza subsidios redundando en una mayor equidad y sostenibilidad del servicio. Este tipo de subsidios ha permitido dar apoyo a aquellas familias que atraviesan una 
situación económica delicada y que no pueden afrontar el pago completo de la factura, garantizando así el derecho humano de acceso al agua potable a este grupo de usuarios" (AySA, 2018: 6).

Si se analiza el saldo pendiente de cobro ${ }^{32}$ en relación al total de facturación por los servicios de agua potable y/o saneamiento ${ }^{33}$ se observa que éste fue incrementándose hasta presentar su valor máximo en 2011 y 2012 (34\%), para culminar registrando un 25\% en 2016 (Gráfico 7). Realizar una quita total de subsidios, para aquellos años, hubiera profundizado las limitaciones existentes por lo que la gradualidad implementada contuvo ese posible impacto ${ }^{34}$. Si bien en 2016 este valor presentó un descenso de 9 puntos porcentuales, resta conocer qué efecto tuvieron los incrementos tarifarios posteriores pero aún no se cuenta con los datos necesarios para efectuar este análisis.

\section{Gráfico 7.}

Saldo pendiente de cobro sobre facturación total usuarios residenciales AySA (2006-2016) (en porcentaje)

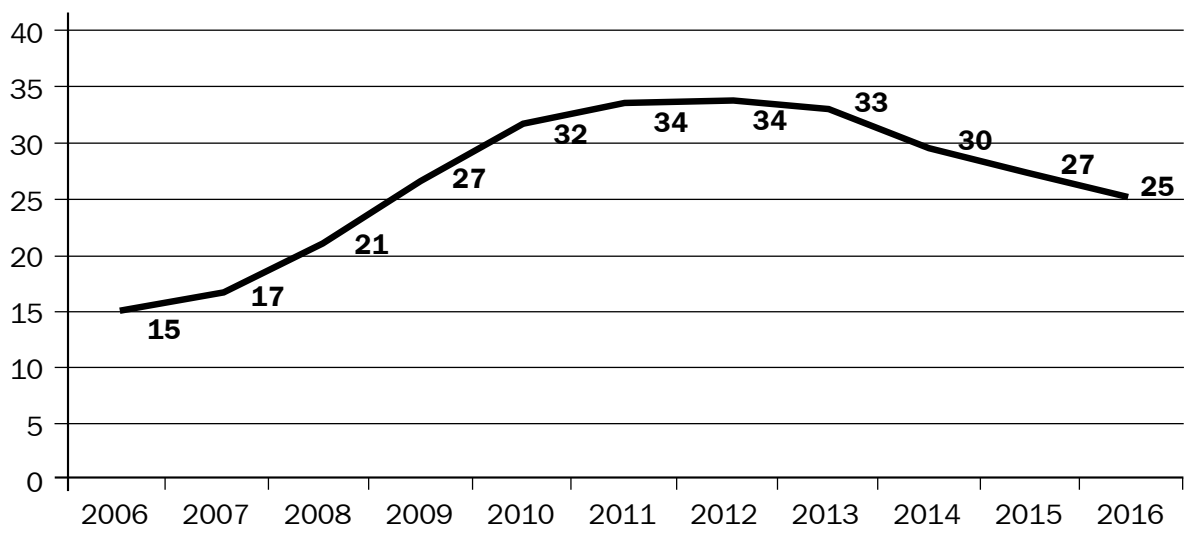

Fuente: elaboración propia en base a Informes Anuales de AySA (2006-2016).

Siguiendo la propuesta analítica de McDonald y Ruiters (2012), otro aspecto que puede observarse para considerar el grado de equidad con el que se presta el servicio refiere a la accesibilidad, es decir a la cantidad y calidad en la que el mismo es ofrecido. A este respecto, en materia de cobertura ${ }^{35}$ del servicio de agua potable, el déficit total existente al momento de la rescisión era del $22 \%$ 
(2.062.000 habitantes) y del $41 \%$ (3.832.000 habitantes) para los desagües cloacales. A fin de atender esta situación, mediante la implementación del Plan Director de Saneamiento 2006-2020, AySA se propuso alcanzar, para el 2011 , el $100 \%$ de cobertura en el servicio de agua y el $80 \%$ en los desagües cloacales. En el período 2012-2020 se preveía mantener la cobertura total de agua y alcanzar el $95 \%$ respecto de las cloacas. Aun cuando, para esos años, no se cumplieron con esas metas, se presentó una evolución ascendente en la cantidad de población incorporada a las prestaciones durante 2006-201736. En cuanto al servicio de agua potable, la cobertura se incrementó en 2015, en 6 puntos porcentuales y 9 en 2017: el 78\% registrado en 2006 pasó al $84 \%$ en 2015 y al $87 \%$ para el 2017. Para los desagües cloacales los datos muestran para 2015 un crecimiento de 5 puntos porcentuales respecto de 2006 (del 59\% pasó al 64\% de cobertura), mientras que en 2017, el aumento fue de 10 puntos (69\%). En lo que refiere a las nuevas áreas incorporadas a la concesión, la cobertura registrada en 2017 fue del 38\% para agua potable y del $27 \%$ respecto del servicio de cloacas.

Al desagregar los datos por regiones, los mayores incrementos en la cobertura de agua potable se presentaron en la zona oeste (La Matanza, Morón y Tres de Febrero) y la zona suroeste (Almirante Brown, Esteban Echeverría y Lomas de Zamora). En la primera, la población servida a 2017 creció 25 puntos porcentuales más que en 2006 , se pasó del $55 \%$ al $80 \%$. Respecto de la zona suroeste, el aumento se dio en 10 puntos porcentuales más que al inicio de la concesión, del $50 \%$ se alcanzó el $60 \%$. La cobertura en desagües cloacales acompañó este crecimiento aunque en menor nivel. La zona oeste presentó el incremento más alto de toda el área concesionada (17 puntos más que en 2006, de 43\% al 60\%), seguida por la zona norte (San Fernando, Tigre, San Isidro, San Martín y Vicente López) (13 puntos, de 54\% al 67\%), la zona suroeste (13 puntos, de $16 \%$ al $29 \%$ ) y la zona sureste (Avellaneda, Lanús y Quilmes) (13 puntos, de $49 \%$ al $62 \%)^{37}$.

Para atender las necesidades de cobertura de aquellas comunidades vulnerables, AySA continúo con la implementación de dos metodologías desarrolladas por AASA desde 2003 y 2004: 1) el Modelo participativo de gestión $(M P G)$ y 2) el Plan Agua + Trabajo $(A+T)$. A través del MPG, trabajaban de manera conjunta, las comunidades, los municipios y la empresa. Esta última aportaba la mayor parte del financiamiento de los proyectos, a la vez que, supervisaba técnicamente las obras y capacitaba a los vecinos de los barrios. Los municipios, responsables de la dirección técnica de los trabajos, eran los 
que priorizaban los proyectos y brindaban los materiales necesarios para su realización. Finalmente, los vecinos aportaban la mano de obra y recibían a cambio descuentos en sus facturas.

El $A+T$ fue un proyecto del gobierno nacional, con el que buscó disminuir el riesgo sanitario de la población sin acceso al servicio, reducir los costos de expansión en los barrios de bajos recursos y a la vez, crear empleo con el establecimiento de cooperativas de trabajo integradas por beneficiarios de planes de asistencia social y desocupados. AySA financia, diseña los proyectos, tiene a cargo la logística de los materiales y la supervisión técnica de las obras. Asimismo participa, junto con el Instituto de Asociativismo y Economía Social (INAES) y el Instituto Leopoldo Marechal (dependiente del Sindicato Gran Buenos Aires de Trabajadores de Obras Sanitarias), de la capacitación a las cooperativas. Éstas brindan la mano de obra y reciben una remuneración mensual de acuerdo al avance certificado de los trabajos. Por su parte, los municipios definen las áreas de expansión, administran los fondos otorgados por AySA y ejecutan e inspeccionan las obras. Desde 2008, este mismo método fue incorporado para la extensión de los desagües cloacales, mediante el Plan Cloaca + Trabajo (Informe al usuario, 2008 y 2015).

De acuerdo con los datos disponibles ${ }^{38}$, en el marco del MPG, el total de obras concluidas permitieron la conexión de 48.530 habitantes a los servicios. Por su parte, los planes $\mathrm{A}+\mathrm{T}$ y $\mathrm{C}+\mathrm{T}$ mostraron en total, para el período, un incremento de 30 veces más respecto de la cantidad de módulos de obras finalizadas (de 28 pasaron a 856) cubriendo a 1.409 .760 habitantes, casi 25 veces más que la población cubierta en 2006 . El mayor aumento se dio en la extensión de la cobertura de agua potable, pues la cantidad de módulos para 2017 fue de 753 frente a los 28 iniciales, con una población servida de 1.310.942 habitantes. En el caso de los desagües cloacales de 1 módulo en 2008, el período culminó con 103 finalizados cubriendo a 98.818 habitantes.

Finalmente, esta activa participación estatal sobre las prestaciones puede observarse también al analizar los datos en materia de inversión. El Gráfico 8 muestra que, durante el período en estudio (2006-2016), hubo un aumento constante de la inversión presupuestada y de la ejecutada, alcanzando ambas su máximo valor en el 2015. Sin embargo, este año no fue el de mayor porcentaje de ejecución de las inversiones. Los registros más altos se dieron en los años 2007 (98\%), 2011 (97\%) y 2014 (92\%). En cuanto a la variación presentada respecto de 2006, la inversión presupuestada creció 16 veces, mientras que la ejecutada 27. 


\section{Gráfico 8.}

Inversión presupuestada e inversión ejecutada AySA (2006-2016)* (en miles de pesos, a valores constantes** y porcentaje)

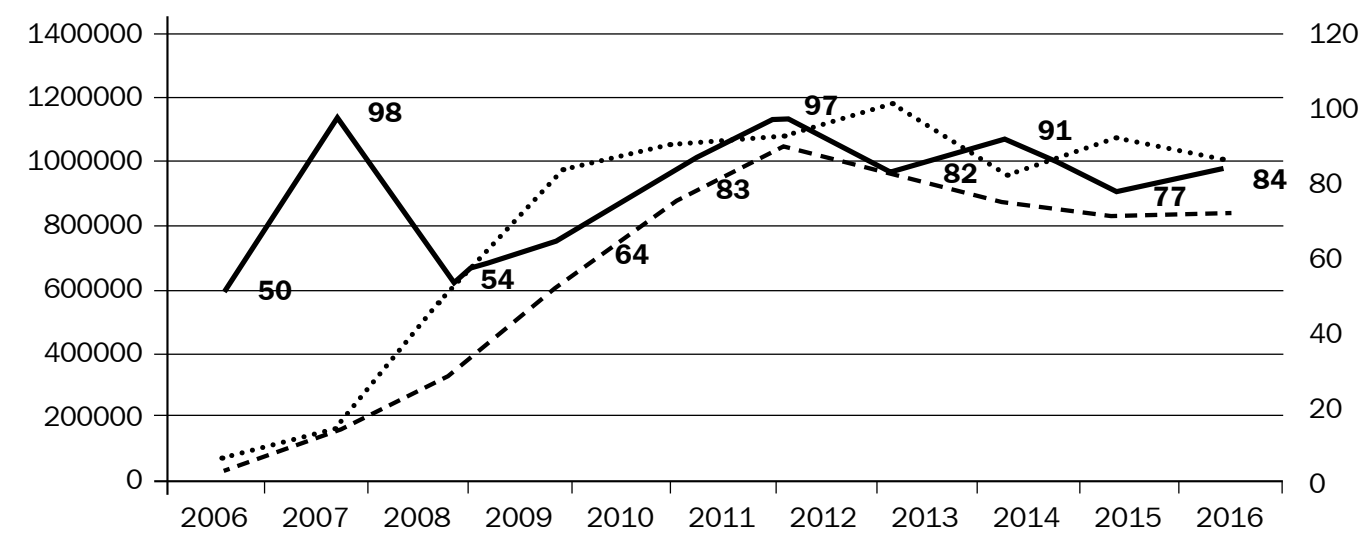

....... Inversión presupuestada _--- Inversión ejecutada — — de ejecución de las inversiones

*Al no contarse con el dato de la inversión presupuestada para el año 2013, los valores para ese año no son presentados en el gráfico. // **IPI base $2004=100$.

Fuente: elaboración propia en base a Informes Anuales de AySA (2006-2016).

Para referir a los criterios de rendición de cuentas y transparencia es necesario caracterizar brevemente el marco regulatorio establecido por la Ley $\mathrm{N}^{\circ}$ 26.221 (02/03/07). En este esquema pueden distinguirse tres ámbitos de acción (Cuadro 3): 1) el de política y supervisión, 2) el de control y 3) el de auditoría y fiscalización. Para el período 2007-2015, el primer ámbito estaba integrado por: a) el MPLAN que tenía a su cargo el dictado de normas complementarias, la aprobación del plan de negocios y la supervisión del desenvolvimiento de la empresa; b) la Secretaría de Obras Públicas (SOP) que se desempeñaba como autoridad funcional entre el concedente y el concesionario y c) la Subsecretaría de Recursos Hídricos (SSRH) establecida como autoridad de aplicación y responsable de impartir políticas, ejercer el poder de policía y control en materia de prestación del servicio. Con el cambio de gestión en diciembre de 2015, estas funciones quedaron a cargo del Ministerio del Interior, Obras Públicas y Vivienda (MIOPyV) y la Secretaría de Infraestructura y Política Hídrica (SlyPH) pasó a desempeñarse como la autoridad de aplicación. En materia de control se establecieron dos organismos, la Agencia de Planificación (APLA) y el Ente Regulador de Agua y Saneamiento (ERAS). La primera debe intervenir en la 
elaboración de los planes y proyectos, el desarrollo de las obras, la elaboración de los estudios de impacto ambiental y el establecimiento de las metas de calidad. Por su parte, el ERAS tiene que fiscalizar la calidad del servicio, verificar el cumplimiento del contrato de concesión y proteger los intereses de los usuarios. Por último, en el ámbito de auditoría y fiscalización, se dispuso la conformación de una Comisión Fiscalizadora, integrada por el Estado Nacional (dos representantes de la Sindicatura General de la Nación — SIGEN_ y uno por los trabajadores). Quedando la auditoría externa en manos de la Auditoría General de la Nación (AGN) y de un grupo de auditores externos, técnicos y económicos (Plan de Saneamiento de AySA, 2006).

\section{Cuadro 3.}

Esquema regulatorio de Agua y Saneamientos Argentinos S.A.

(Instituciones a partir de diciembre de 2015)

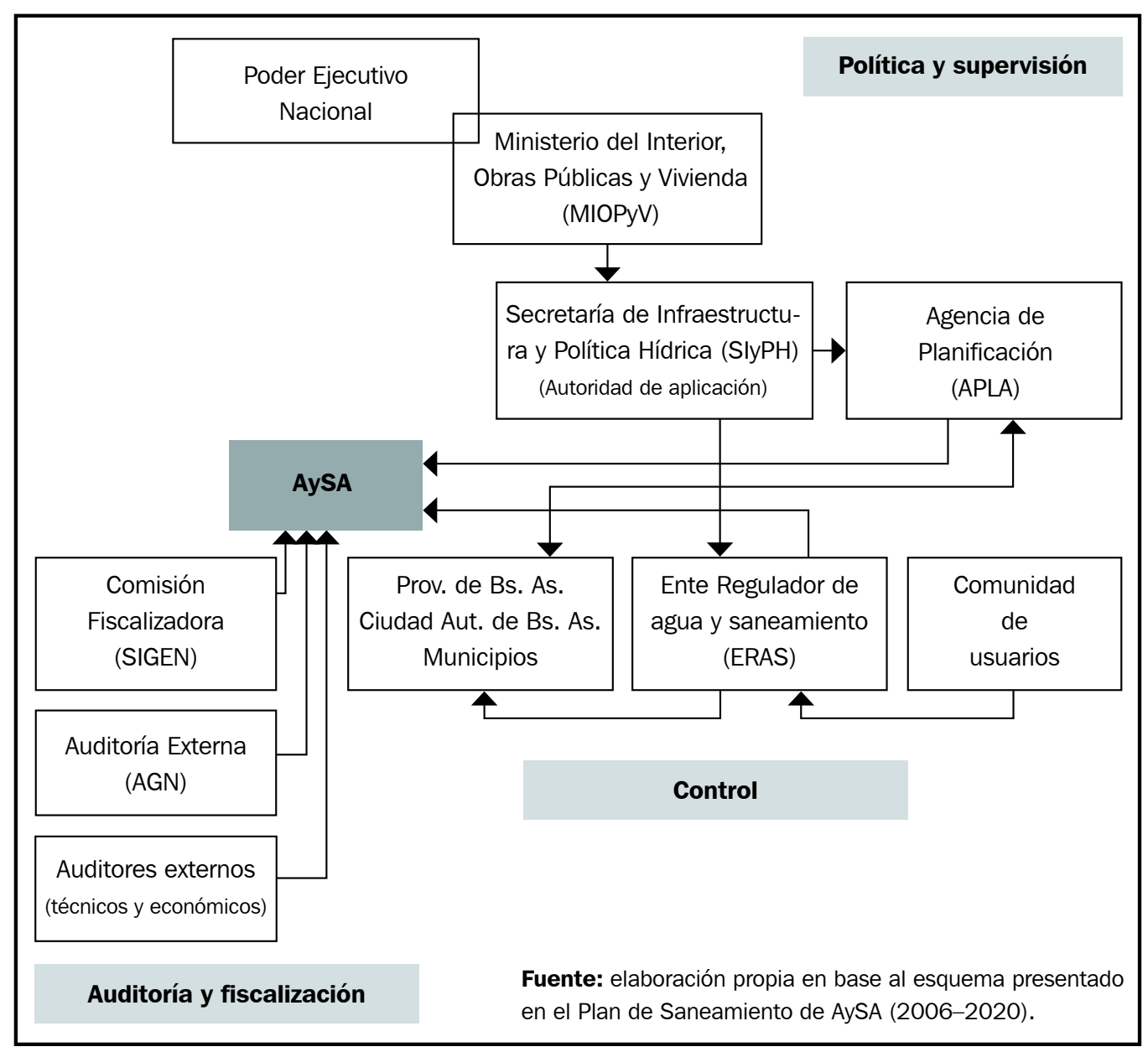


Este régimen de múltiples autoridades presenta superposiciones de funciones entre los organismos y entes diseñados, y a la vez, tiende a la centralización de competencias en las autoridades de la Administración central. Esta situación se acentuó con el cambio de gobierno producto de la reducción de los organismos intervinientes en las definiciones de política y supervisión. La ostensible injerencia asignada al Ministerio a cargo y sus respectivas dependencias pone en cuestión la independencia de los organismos de control propuestos. A diferencia de las facultades y obligaciones que poseía el Ente Tripartito de Obras y Servicios Sanitarios (ETOSS) ${ }^{39}$ (aprobación de los cuadros tarifarios y los planes de mejoras y expansión), al ERAS sólo le caben funciones de control (niveles de calidad, contabilidad regulatoria y benchmarking). Dentro de sus competencias no figuran el establecimiento de las tarifas ni la fijación y modificación de las metas de expansión del servicio, estas funciones son asumidas por la Secretaría de Infraestructura y Política Hídrica. Tampoco tiene facultad para sancionar a AySA, sólo puede amonestar a los directivos o gerentes de la empresa. Por otra parte, el modo de elección de las autoridades en el ERAS y la APLA, los vincula directamente al poder político. EI PEN designa a los integrantes de los respectivos Directorios, uno de manera directa y los dos restantes por recomendación de los Poderes Ejecutivos de la Ciudad Autónoma de Buenos Aires y de la Provincia de Buenos Aires. La presidencia del Directorio del ERAS queda a cargo del representante del gobierno nacional mientras que, en el caso de la APLA, ésta es desempeñada por el Secretario de Infraestructura y Política Hídrica. Dicho funcionario no sólo ejerce la representación legal, sino que su voto vale doble en caso de producirse un empate. Esta designación sin concurso público, les resta independencia a los organismos pues se originan compromisos políticos con las autoridades de las jurisdicciones, que pueden interferir el desarrollo de las gestiones. Desde la técnica regulatoria esto concita diversos cuestionamientos debido a la dependencia que genera respecto del PEN pero, desde el punto de vista político, asegura que las presidencias se mantengan afines a sus disposiciones.

En lo que respecta a la información necesaria para llevar adelante la regulación y el control de lo actuado por AySA, se dispuso que la compañía debía registrar la información relativa a la calidad, operación y mantenimiento de los servicios prestados a fin de estar disponibles ante los pedidos de la autoridad de aplicación, de la APLA y el ERAS. Asimismo debe elaborar diferentes tipos de informes (sobre niveles de servicio, anuales, periódicos y adicionales) que está obligada a publicar. Cabe consignar que al inicio de la gestión, AySA fue reticente en la entrega de información aun cuando el marco regulatorio la 
obligaba a brindarla. La empresa reiteradamente había eludido al ente respecto de la entrega de información financiera que, por el contrario, enviaba a la Subsecretaría de Recursos Hídricos. Al carecer ésta de capacidad técnica para analizarla, la remitió al ERAS y de este modo comenzó a analizarla. Asimismo, la intervención del ERAS en relación al presupuesto de AySA, se da formalmente desde 2008 (con anterioridad no se los enviaban) y se le solicita que se expida, en un plazo breve, sobre lo que ya fue aprobado por el Congreso Nacional, constituyendo una mera formalidad.

En cuanto al criterio de participación de los ciudadanos en la gestión de los servicios, AySA no cuenta con este tipo instancias. La participación institucionalizada está circunscripta a cuestiones de control a través del accionar de las asociaciones de usuarios y consumidores en la Sindicatura de Usuarios que funciona bajo la órbita del ERAS. La estructura y funciones de esta Sindicatura se asemejan a las de la Comisión de Usuarios del ETOSS ${ }^{40}$. Sus recursos institucionales y de información se mantuvieron acotados, pues sus pronunciamientos no son vinculantes, la información requerida respecto de la empresa es provista por el Ente y su conformación quedó restringida a asociaciones registradas con actuación a nivel nacional. A esto se suma que, a diferencia de su antecesora, el nuevo marco regulatorio estableció que sus miembros se desempeñen ad-honorem. De acuerdo a los representantes de las asociaciones, esta disposición conlleva ciertas dificultades para su funcionamiento ${ }^{41}$. En lo que respecta a la APLA, si bien por su función (establecimiento y modificación de la metas de expansión del senvicio) sería deseable la participación de los usuarios, su intervención se da indirectamente a través de las demandas y propuestas presentadas por los intendentes de los diversos municipios que integran la Comisión Asesora de la Agencia.

El marco regulatorio estableció también en su Art. № 54 la creación en el ámbito del ERAS de un Defensor del Usuario, elegido mediante concurso público y sujeto, al igual que los Directores, al régimen de incompatibilidades de funcionarios públicos. Éste tiene por función, «representar institucionalmente los intereses de los usuarios en las audiencias públicas, así como en cuestiones contenciosas o de procedimientos administrativos en las que el ente regulador sea parte y los derechos de los usuarios pudieran estar afectados por la decisión». Tras más de una década de establecido el marco y luego de siete años de efectuado el llamado a concurso, el cargo fue adjudicado por el plazo de cuatro años mediante la Resolución ERAS № 59/16 (30/12/16). Otro procedimiento público de participación disponible para la ciudadanía son las audiencias públicas relativas a las adecuaciones tarifarias. Su alcance como espacio deliberativo 
encuentra limitaciones no sólo por la efectiva participación ciudadana que queda circunscripta a funcionarios, expertos y representantes de asociaciones de usuarios sino también por el carácter no vinculante de sus resoluciones. Parece constituir más un requisito formal que una instancia amplia de deliberación.

Por último y vinculados a estas cuestiones, vale considerar los datos referidos a la atención de los usuarios (reclamos recibidos y respondidos por la empresa). Para el período 2006-2017, se observa que en promedio se registraron cerca de 500 mil reclamos por año. Entre los motivos que los originaron se encontró que los reclamos por cuestiones técnicas explicaron el $80 \%$ del total (44\% por problemas en el servicio de agua y $36 \%$ en el servicio de saneamiento) siendo los reclamos comerciales (por facturación, errores de medición, etc.) los de menor cuantía con un 19\%. Asimismo, el nivel de respuesta alcanzado fue de casi el 100\% pues tan sólo 6158 casos quedaron sin ser respondidos dentro del tiempo estipulado (Informes Anuales de AySA, 2006-2017). Si se observan las estadísticas elaboradas por el ERAS ${ }^{42}$, los valores registrados son considerablemente inferiores: la cantidad de reclamos por año fue, en promedio, de 5600 $\operatorname{casos}^{43}$. Sin embargo, las razones técnicas son también las que explican el mayor porcentaje de reclamos con un 94\% (43\% son urgencias, 37\% por el servicio de agua y $14 \%$ por el servicio de saneamiento), mientras que el $6 \%$ restante se debieron a razones de índole comercial (Estadísticas ERAS, 2007-2017).

\section{REFLEXIONES FINALES}

Tras considerar los criterios propuestos por McDonald y Ruiters (2012) para analizar el desempeño de AySA, se evidenció una significativa ampliación de la cobertura que tuvo como eje central la activa participación estatal en el incremento de las transferencias e inversiones entregadas. Sin embargo, es preciso observar también que durante el período 2006-2015 (con excepción de los años 2008 y 2009), AySA no pudo cubrir el total de sus gastos corrientes con ingresos propios. Asimismo, las obras realizadas se solventaron fundamentalmente con transferencias del Estado Nacional. A partir de 2016, con la llegada del nuevo gobierno, este esquema se modificó mediante la implementación de un significativo aumento tarifario. Como consecuencia de ello, para 2016, se revirtieron los resultados económicos negativos que venía presentando la empresa aunque con un impacto directo y regresivo sobre los usuarios de menores ingresos. Situación que también puede explicar, en parte, la ampliación exponencial de los beneficiarios de la tarifa social en sus diversas 
modalidades. A partir de 2017, estos aspectos se profundizaron producto de la implementación de nuevas subas tarifarias que fueron justificadas por el contexto inflacionario y la incorporación de nuevos partidos al área concesionada. Respecto de las transferencias de capital, éstas permanecieron a cargo del Estado y para 2017 fueron incrementadas en un 21\% respecto de 2015.

A futuro, de acuerdo con lo planteado por la empresa, se tiene por objeto avanzar hacia la generalización de la micromedición de los consumos, es decir, pasar a facturar por el volumen de los consumos reales, en vez de considerar la superficie de los inmuebles. De acuerdo a lo expuesto, con estos cambios en los criterios de tarifación se procurará incentivar una mayor racionalidad en el uso del recurso. Queda por ver entonces de qué manera se realizará dicha generalización teniendo en cuenta, por ejemplo, las limitaciones estructurales que se presentan en los edificios de propiedad horizontal existentes y cómo serán cubiertos los costos de instalación de los medidores individuales. Una efectiva implementación de la micromedición no sólo deberá evitar el derroche del recurso sino que también tener en consideración el poder adquisitivo de los usuarios, para propiciar un acceso más equitativo al servicio.

En cuanto a los criterios de rendición de cuentas y transparencia se observó que la regulación y el control del servicio alcanzaron formalmente mayor cercanía al poder político y con ello, una mayor discrecionalidad. Este tema no debería ser cuestionado per se sino ser considerado a la luz de la mayor intervención que tuvo el Estado en la prestación (crecientes transferencias e inversiones directas en infraestructura). ¿Por qué crear dos organismos de control con restricciones de diseño y de funcionamiento efectivo, si en ese nuevo esquema no eran relevantes? Frente a esto, surge la necesidad de redefinir una clara estrategia regulatoria, donde el contralor normativo y social -sea la forma que adquiera (centralizada o descentralizada) - se conciba como condición para asegurar buenos servicios. Vinculado a esto, la participación de los ciudadanos también presentó limitaciones pues como se señalara su participación institucionalizada se circunscribió a cuestiones de control a través de lo actuado por las asociaciones de usuarios y consumidores.

En síntesis, el regreso del Estado a la gestión del servicio implicó un mayor compromiso político que se tradujo en amplios aportes de recursos estatales. Habiendo adoptado la corporatización una forma progresista de prestación, nuevos interrogantes se plantean respecto del significado de "lo público" y su concreción práctica a partir del cambio de gobierno en diciembre de 2015. El énfasis centrado en los incrementos tarifarios, la ausencia de transferencias corrientes a partir de 2017 y los cambios en la institucionalidad del sector 
¿constituyen indicios de una incipiente reconfiguración del servicio? ¿Se encamina nuevamente la prestación hacia una lógica de mercantilización? ¿Qué implicancias tendrá el nuevo esquema de autoridades sobre la gestión? Dar respuesta a estos interrogantes implicará seguir profundizando en el estudio de los criterios presentados a la luz de nuevos datos. Asimismo, a fin de completar la caracterización del desempeño de AySA, restan analizar los criterios de calidad de trabajo, ética pública y participación considerando a los trabajadores de la empresa. Ambas tareas serán abordadas en futuros trabajos.

\section{NOTAS}

1 Desde su creación en 1912, la empresa estatal, Obras Sanitarias de la Nación (OSN), había estado a cargo de los servicios en la mayor parte del territorio nacional, garantizando la cobertura en aquellas regiones menos desarrolladas. Esta situación se modificó a partir del $1^{\circ}$ de enero de 1980, cuando la dictadura cívico-militar (19761983) dispuso la descentralización de los senvicios hacia las provincias. La compañía se dividió en 161 sistemas de agua potable y cloacas y OSN quedó a cargo exclusivamente de la prestación en la Ciudad de Buenos Aires y en trece partidos del Conurbano Bonaerense. En 1993, el servicio fue concesionado a manos privadas, por lo que la empresa Aguas Argentinas S.A. se hizo cargo de las prestaciones hasta marzo de 2006.

2 AySA fue creada bajo el mandato de Néstor Kirchner, quien ejerció la presidencia de la República Argentina durante el período 20032007. Fue sucedido por Cristina Fernández de Kirchner quién estuvo a cargo del gobierno durante dos períodos consecutivos: 2007-2011 y 2011-2015. En diciembre de 2015, asumió Mauricio Macri, candidato de Cambiemos, alianza constituida por partidos opositores a las anteriores gestiones.

${ }^{3}$ Con la promulgación de la Ley № 25.561 de Emergencia Pública y Reforma del Régimen Cambiario (07/01/02), el gobierno de Eduardo Duhalde instrumentó la devaluación del peso, poniendo fin al régimen de Convertibilidad que establecía

una paridad cambiaria fija (un peso argentino = un dólar estadounidense). Se dispuso la pesificación de precios y tarifas, dejando sin efecto las cláusulas indexatorias de ajuste presentes en los contratos de la Administración Pública. El Poder Ejecutivo Nacional fue facultado para renegociar esos contratos, inclusive los de los servicios públicos privatizados. Se determinó también el congelamiento de los niveles tarifarios hasta tanto se efectuara la revisión integral de esos contratos. ${ }^{4}$ El incremento en un $88 \%$ de la tarifa media residencial (desde mayo 1993 a enero 2002) le había permitido obtener una rentabilidad promedio del $20 \%$, que superó al $11,21 \%$ proyectado en la oferta. Asimismo, la incorporación de diversos cargos fijos había influido de manera significativa en ese aumento altamente regresivo. En relación a las inversiones previstas, el grado de ejecución en el primer quinquenio (1993-98), fue sólo del 58\%. En el segundo (1999-2003), las inversiones realizadas en los años 1999 y 2000 se correspondieron en su totalidad con las previstas pues se retrasó dos años la revisión de las metas y fueron aprobadas ex-post. En el 2001 el grado de ejecución fue del $62 \%$, mientras que en el 2002 caería al 19\%. Desde 1993 a 2002, la expansión de la cobertura del servicio de agua potable, sólo cubrió un $79 \%$ de los habitantes frente al $88 \%$ estipulado en el contrato. En el servicio de cloacas sólo alcanzó el $63 \%$ frente al $74 \%$ previsto (ETOSS, 2003). 
5 Sus accionistas extranjeros (Suez — socia mayoritaria-, Vivendi Universal S.A. y Aguas de Barcelona S.A.) decidieron mantener la demanda que habían presentado ante el Centro Internacional de Arreglo de Diferencias Relativas a Inversiones (CIADI).

6 Los datos presentados están calculados en base a la información presentada por AySA en sus ejecuciones presupuestarias.

${ }^{7}$ Aunque la empresa se constituyó en 2006, fue a partir de 2008 cuando comenzó a recibir este tipo de transferencias.

${ }^{8}$ Este tema será abordado con mayor detalle a continuación.

9 Para más detalles ver Rocca (2013).

10 A esa fecha la factura media era de $\$ 27,40$. ${ }^{11}$ A 2015, las transferencias corrientes crecieron casi cuatro veces más respecto de 2008 . Si se consideran los datos de 2016 el incremento fue de casi cinco veces. Como se señalara, en 2017 , el Estado Nacional no realizó transferencias corrientes a la empresa.

12 La reestatización del servicio conllevó el establecimiento de un nuevo marco regulatorio (Ley $N^{\circ}$ 26.221, 02/03/07). En su «Anexo E Régimen tarifario" se dispuso que la Autoridad de Aplicación debía aprobar el RANT, donde se especificarían los valores adoptados por los componentes de la tarifa según el tipo de usuario. De este modo, mediante la Disposición SSRH N 45/10 (16/11/10) fue aprobado el RANT, que entró en vigencia el 14 de febrero de 2011. AySA tenía un plazo máximo de un año calendario desde aquella fecha para emitir las facturas acorde al régimen aprobado (Art. 3). La adecuación del sistema de facturación se registró finalmente a partir de mediados de 2013.

13 Se consideraban tres categorías de inmuebles: residenciales, no residenciales —ambas se subdividían según tuvieran o no unidades abastecidas - y baldíos.

${ }^{14}$ Se entiende como tal a la provisión de agua potable con destino a ser utilizada fuera del área servida por el concesionario.

${ }^{15} \mathrm{El}$ cálculo se expresaba de esta manera: TBB= $\mathrm{K} * \mathrm{Z} * \mathrm{TG} *(\mathrm{SC} * \mathrm{E}+\mathrm{ST} / 10)$; TBB mínima.

${ }^{16} \mathrm{~A}$ partir de 2007 la alícuota quedó divida entre la Agencia de Planificación (APLA) (1,120\%) y el Ente Regulador de Agua y Saneamiento (ERAS) (1,550\%).

17 Para el período 1993 (mayo)-2002 (enero), la tarifa media residencial se incrementó un 88\%: de \$14,56 llegó a \$27,40 (ETOSS, 2003). De acuerdo a los datos presentados por Azpiazu y Forcinito (2004) para ese mismo plazo, el factor "K" aumentó un 31\%, el Cargo de infraestructura para las conexiones del agua potable sufrió un aumento del 38,5\% mientras que en relación a los desagües cloacales el incremento fue del $45,7 \%$. Si bien en mayo de 1998 , el SUMA sufrió una disminución del $47 \%$, a partir de ese momento, se fue incrementando hasta registrar para enero de 2002 un aumento del 63\%. Significativos aumentos registró también el Cargo por incorporación al servicio (9,6 \%) y los consumos libres disminuyeron en $20 \mathrm{~m}^{3}$.

18 Hasta mayo/junio de 2013 la facturación incluyó todos estos componentes. A partir de ese período se incorporó el Aporte Universal Diario (AUD) fijo y variable.

19 Azpiazu y Forcinito (2004: 99) señalan que los costos reales de los servicios recayeron asimétricamente según los estratos de ingresos. Al considerar los datos de mayo de 2002, para el decil de mayores ingresos de la población del Gran Buenos Aires, la relación entre el costo del servicio y sus ingresos era del 1,3\%. En el caso del decil de menores ingresos, la tarifa cobrada representaba el $9 \%$ de sus ingresos. Mientras que para el promedio de los usuarios implicaba el 1,9\%. ${ }^{20}$ La Resolución Conjunta MECON y MPLAN N ${ }^{\circ}$ 693/11 y 1900/11 (3/11/11) creó el Grupo de Trabajo para el análisis y estudio de la incidencia en los distintos sectores de los subsidios. Este Grupo dispuso los sectores a los que debían retirárseles o disminuir los subsidios.

21 «Desde 2012, cada uno de los usuarios porteños, primero los de los barrios más acomodados, recibirá, junto con la boleta, una declaración jurada donde deberá decir si necesita o no recibir el subsidio. Si asegura que no requiere ser asistido, se le eliminará el beneficio. Si manifiesta, en cambio, necesidad de ser subsidiado, el Gobierno analizará el caso a través del cruce de 
datos previsionales e impositivos y definirá si le corresponde o no. Además, en los próximos días se habilitará un mecanismo para que el usuario que considere que no necesita de la ayuda estatal pueda autoexcluirse inmediatamente" (Diario Página 12, 17/11/11).

22 Esta política se implementó en todos los servicios públicos bajo el argumento de que era necesario adecuar las tarifas para propiciar mayores inversiones y mejoras en las prestaciones. ${ }^{23}$ Este programa consiste en un subsidio al acceso y/o al uso del servicio para aquellos usuarios que no pueden afrontar el pago pleno de las tarifas vigentes. Asimismo el subsidio puede destinarse para la regularización de situaciones de morosidad.

24 «En efecto los cambios tarifarios de la Disposición SSRH $N^{\circ} 19-E / 17$ confluyeron con la caída de la medida cautelar que impidió la aplicación de la Disposición SSRH N 62/16 por lo que se acumularon dos ajustes tarifarios que podían generar un impacto negativo relevante en las facturas de los usuarios (...) Teniendo en cuenta ello, se trabajó en la profundización y difusión del Programa de la Tarifa Social en el área afectada, con el objetivo de mitigar el impacto que el incremento en el monto de las facturas pudieran producir en las economías de estos hogares. A partir de $1^{\circ}$ de enero de 2018 se comenzaron a aplicar las tarifas aprobadas por la Disposición SSRH N 19/17, quedando pendiente el tratamiento de los retroactivos correspondientes" (AySA, 2018: 10).

${ }^{25}$ Con la firma del Acta Acuerdo (12/05/16) y el Acta Complementaria (5/07/16) entre el Ministerio de Infraestructura y Servicios Públicos de la Provincia de Buenos Aires y el Ministerio del Interior, Obras Públicas y Vivienda de la Nación (MIOPyV) (ratificadas por Ley Provincial $N^{\circ}$ 14.830 y las Resoluciones MIOPyV N 655/16 $(13 / 05 / 16)$ y $N^{\circ} 425-E / 16(01 / 11 / 16)$ el área de concesión se amplió. Se incluyeron a los partidos de Escobar, Florencio Varela, José C. Paz, Malvinas Argentinas, Merlo, Moreno, Presidente Perón y San Miguel totalizando 25 partidos del Conurbano Bonaerense y la Ciudad Autónoma de Buenos Aires. La superficie total cubierta pasó de
1811 km² a 2949 km², abarcando una población de 13.558.139 habitantes.

26 El Programa de Tarifa Social se había establecido durante la gestión de AASA a través de la Resolución ETOSS N²/02 (28/01/02). Su implementación se fundamentó en la necesidad de contemplar la crítica situación socioeconómica que atravesaba una parte importante de los usuarios de los servicios. Posteriormente, se modificaron dos anexos de la misma: el descuento fijo pasó a aplicarse sobre el monto total de la factura, se brindó mayor flexibilidad al cambio del importe de los módulos y se amplió la cantidad de integrantes de la Comisión Ejecutiva a cargo de la realización del Programa (Resolución ETOSS N 13/02, 08/03/02). Otras resoluciones establecieron: la inclusión de las instituciones sin fines de lucro (Resolución ETOSS N 10/03, 04/02/03), el incremento de la cantidad de módulos asignados a cada jurisdicción (Resolución ETOSS N 5/04, 09/02/04; 130/04, 10/01/05 y 58/05, 22/06/05), la definición e incorporación del "caso social" (residencial y no residencial) y la abstención al corte de los servicios a ese tipo de usuario (Resolución ETOSS N 112/04, 19/11/14) y el plan de regularización de las deudas para usuarios no residenciales y los requisitos de permanencia para las instituciones sin fines de lucro (Resolución ETOSS N²1/05).

27 El criterio de inclusión considera los ingresos disponibles del hogar y los ingresos totales anuales de la institución formalmente registrados. Por su parte, el criterio de asignación del descuento para la modalidad tarifa social (usuarios residenciales) tiene en cuenta la composición del gasto en los servicios optativos (telefonía fija y/o celular, internet y televisión por cable). De este modo, los hogares con menores gastos en ese rubro, reciben un mayor descuento pues se considera que requieren de más ayuda económica para pagar los servicios de agua potable y saneamiento. 28 Toma en consideración hogares: con ingresos limitados a gastos de subsistencia, monoparentales, con adultos mayores a cargo, integrados por personas con discapacidad y/o enfermedades crónicas o que utilizan como vivienda inmuebles con otro destino. 
${ }^{29} \mathrm{Si}$ bien es un formulario que puede ser autoadministrado, los usuarios pueden también concurrir (con la "Solicitud de ingreso-hogares») a los lugares de atención establecidos para cumplimentar la gestión.

30 «El procedimiento que permite ponderar la importancia de estos gastos consiste en comparar su monto total con el Valor de Referencia Primario (equivalente a 2 jubilaciones mínimas) en términos porcentuales" (Resolución ERAS $N^{\circ}$ 19/16, 26/05/16).

${ }^{31} \mathrm{El}$ descuento máximo previsto es del 100\%, el medio del 60\% y el mínimo del 30\%.

32 Se entiende por saldo pendiente de cobro a aquella "facturación pendiente de cobro al final del período informado (deudores por ventas)" (Informe Anual AySA, 2006: 846).

33 "Total de la facturación en el período, por los servicios de agua potable, incluyendo agua exportada, y saneamiento, incluyendo aguas residuales importadas (no debe incluir impuesto "IVA", sí en cambio otros impuestos que forman parte del costo de operación)" (Informe Anual AySA, 2006: 846).

34 No debe soslayarse que 2011 fue un año electoral por lo que una medida de esa índole podría haber acarreado efecto negativos de cara a la reelección presidencial.

35 Los datos presentados están calculados en base a la información presentada por AySA en sus Informes Anuales (2006-2017).

${ }^{36} \mathrm{Al}$ comparar las unidades funcionales (incluye usuarios residenciales, no residenciales y baldíos de ambos servicios) a diciembre de 2006, con el total existente en diciembre de 2017 , se observó un incremento del 16\% para ambos servicios. Los distritos que más crecieron fueron los de Ezeiza, Tristán Suárez y Spegazzini y el de Esteban Echeverría. Para los primeros, el aumento fue del triple: de 11.921 unidades funcionales pasaron a 36.216. En Esteban Echeverría, éstas se duplicaron de 37.239 en 2006 , se registraron 77.880 en 2017.
37 Respecto de 2015, el impacto por regiones sufre algunos cambios. Aunque la cobertura en la región oeste sigue siendo la que más creció (13 puntos), le siguen: la región sureste (10 puntos), la suroeste (9 puntos) y la norte (6 puntos).

38 Para analizar la evolución de estos programas se utilizó la información provista en los Informes Anuales de AySA (2006-2017). A partir de 2012 en adelante, no hubieron obras bajo el MPG por lo que los datos aquí presentados comprenden el período 2006-2011. Respecto de los programas $\mathrm{A}+\mathrm{T}$ y $\mathrm{C}+\mathrm{T}$, se consideraron los datos de todo el período bajo estudio.

39 Durante la concesión a AASA y hasta el cambio de marco regulatorio, la regulación del servicio estuvo a cargo del ETOSS, agencia creada por el Decreto N 999/92 (30-06-92).Para más detalles sobre su diseño y desempeño ver Rocca (2012).

40 Esta Comisión fue creada en abril de 1999 (Resolución ETOSS N³8/99, 28/04/99) e integrada, en principio, por ocho asociaciones registradas a nivel nacional. Esto último constituyó una barrera para la participación de organizaciones vecinales (principalmente del Conurbano Bonaerense) que venían trabajando en relación al servicio.

${ }^{41}$ Algunos de los entrevistados pertenecientes al ERAS fueron muy críticos respecto de los reclamos de financiamiento de las asociaciones. Señalaron que la búsqueda de recursos se presentaba más como un fin en sí misma que como un medio para desarrollar efectivamente su trabajo. AySA había intercedido para restaurar el subsidio, solicitando recursos a través de la SSRH.

42 Estos datos se encuentran disponibles desde el año 2007 en adelante. Los reclamos de 2011 están consignados hasta noviembre y no a diciembre como en el resto de los años.

${ }^{43}$ Aun cuando no es el propósito de este análisis, una explicación de esta diferencia debiera ahondar en el nivel de conocimiento que los usuarios poseen respecto del Ente regulador. 


\section{BIBLIOGRAFÍA}

Alfaro Fernandois, R. (2009). Fomento de la eficiencia de las empresas estatales de agua potable y saneamiento. Serie Recursos Naturales e Infraestructura No 141, LC/L.3010-P. Santiago de Chile: CEPAL.

Azpiazu, D. y Forcinito, K. (2004). «Historia de un fracaso: La privatización del sistema de agua y saneamiento en el Área Metropolitana de Buenos Aires" en D. Azpiazu, A. Catenazzi y K. Forcinito, Recursos públicos, negocios privados. Agua potable y saneamiento ambiental en el Área Metropolitana de Buenos Aires: Universidad Nacional de General Sarmiento, pp. 11-112.

Balanyá, B., Brennan, B.; Hoedeman, O., Kishimoto, S. y Terhorst, P. (Ed.) (2005). Reclaiming Public Water Achievements, Struggles and Visions from Around the World. Ámsterdam: Transnational Institute (TNI) \& Corporate Europe Observatory (CEO).

Bohoslavsky, J.P. (2011). Fomento de la eficiencia en prestadores sanitarios estatales: la nueva empresa estatal abierta. Serie Documentos de Proyectos, LC/W.381. Santiago de Chile: CEPAL.

Castro, J. (2004). "Final Report». Project "Barriers to and conditions for the involvement of private capital and enterprise in water supply and sanitation in Latin America and Africa: seeking economic, social, and environmental sustainability (PRINWASS)", European Commission - 5th Framework Programme, INCO-DEV, Contract ICA4-CT-2001-10041.

Clò, S., Ferraris, M. y Florio, M (2015). "Public Enterprises in a Global Perspective in the Last Decade». Working Paper № 2015-03. Dipartimento di Eeconomia, Management e Metodi Quantitativi, Università degli Studi di Milano.

Florio, M (2013). "Repensar la empresa pública: la nueva agenda de investigación» En D. Chávez y S. Torres (eds.) La reinvención del Estado. Empresas públicas y desarrollo en Uruguay, América Latina y el mundo: Transnational Institute, pp. 29-46.

Ferro, G., Emilio L. y Romero, C. (2011). Eficiencia y su medición en prestadores de servicios de agua potable y alcantarillado. Serie Documentos de Proyectos, LC/W.385. Santiago de Chile: CEPAL.

Florio, M (2014). "The Return of Public Enterprise». Working Paper N 01. Centre for Industrial Studies.

García, A. (1998). "La renegociación del Contrato de "Aguas Argentinas" (o cómo transformar los incumplimientos en mayores ganancias)». Realidad Económica № 159 (1/10 al 15/11) pp. 69-90.

Grant, M. (2015). "Water in public hands: Remunicipalisation in the United States" at Kishimoto, S., Lobina, E. and Petitjean, O (Ed.) Our public water future. The global experience with remunicipalisation. Amsterdam, London, Paris, Cape Town and Brussels: Transnational 
Institute (TNI), Public Services International Research Unit (PSIRU), Multinationals Observatory, Municipal Services Project (MSP) and the European Federation of Public Service Unions (EPSU).

Hachfeld, D. (2008). "The Remunicipalisation of Water -Some Reflections on the Cases of Potsdam and Grenoble». Paper presented at the workshop "The Public Alternatives to Privatisation» during the European Summer University of Attac, 1st to 6th August 2008, Saarbrücken.

Hall, D. y Lobina, E. (2002). "Water privatization in Latin America, 2002", Public Service International Research Unit (PSIRU), University of Greenwich, PSI American's Water Conference, San José, Costa Rica, July.

Hall, D., Lobina, E. y Terhorst, P. (2013). "Re-municipalisation in the early twenty-first century: water in France and energy in Germany". International Review of Applied Economics, Vol. 27, № 2, 193-214.

Hantke-Domas, M. y Jouravlev, A. (2014). Lineamientos de política pública para el sector de agua potable y saneamiento. Serie Documento de Proyectos, LC/W.400. Santiago de Chile: CEPAL.

Kishimoto, S., Lobina, E. and Petitjean, 0 (Ed.) (2015). Our public water future. The global experience with remunicipalisation. Amsterdam, London, Paris, Cape Town and Brussels: Transnational Institute (TNI), Public Services International Research Unit (PSIRU), Multinationals Observatory, Municipal Services Project (MSP) and the European Federation of Public Service Unions (EPSU).

Lee, T. y Jouravlev, A. (1997). Participación privada en la prestación de los servicios de Agua. Modalidades para la participación privada en la prestación de los servicios de agua. Serie medio ambiente y desarrollo $N^{\circ}$ 2, LC/L.1024. Santiago de Chile: CEPAL.

Lentini, E. (2011). Servicios de agua potable y saneamiento: lecciones de experiencias relevantes. Serie Documento de Proyectos, LC/W.392. Santiago de Chile: CEPAL.

McDonald, D. (Ed.) (2015). Servicios públicos en el Sur Global. Mirada crítica a nuevas formas de gestión. Madrid: Capital Intelectual.

McDonald, D. y Ruiters, G. (eds.) (2012). Alternativas a la privatización. La provisión de los servicios públicos esenciales en los países del sur. Barcelona: Icaria Editorial y Transnational Institute.

Pigeon, M., McDonald, D., Hoedeman, O. y Kishimoto, S. (editores) (2013). Remunicipalización: El retorno del agua a manos públicas. Ámsterdam: Transnational Institute.

Ramesh, M., Araral, E. y Wu, X. (2010). Reasserting the Public in Public Services: New Public Management Reforms. Nueva York: Routledge, Taylor and Francis Group. 
Rocca, M. (2012). "Los ciclos económicos y la regulación estatal del servicio de agua potable y saneamiento del Área Metropolitana de Buenos Aires (1993-2007)". Concorrenza e Mercato. Antitrust, Regulation, Consumer Welfare, Intellectual Property, Vol. 19, pp. 699-726.

(2013). "Continuidades y rupturas en el accionar del Estado argentino respecto de los servicios públicos (1976-2010)". Revista Enfoques: Ciencia Política y Administración Pública, Vol. IX, Nº 18, julio, pp. 19-53.

Warner, M. (2008). «Reversing Privatization, Rebalancing Government Reform: Markets, Deliberation and Planning”. Policy and Society 27, pp. 163-174.

\section{DOCUMENTOS}

AySA (2017). "Adecuación tarifaria AySA S.A. Rebalanceo y adecuación de nivel. Análisis y propuesta alternativa 2017".

(2018). "Adecuación tarifaria AySA S.A. Recomposición de nivel. Análisis y propuesta alternativa 2018".

Ejecución presupuestaria AySA (diciembre 2006, mayo 2007, diciembre: 2008 a 2017).

Estadísticas del Ente Regulador de Agua y Saneamiento (ERAS) (2007 a 2017).

ETOSS (2003). «Informe sobre el grado de cumplimiento alcanzado por el contrato de concesión de Aguas Argentinas S.A.» (Nota UNIREN No 73 del 15 de agosto de 2003), septiembre.

Informe al Usuario (2006 a 2015).

Informe Anual Agua y Saneamientos Argentinos S.A. (2006 a 2017).

Plan de Saneamiento de AySA (2006-2020). Acceso universal a los servicios para millones de argentinos.

DIARIOS

Lewkowicz, J. «Empieza la era de los subsidios a la carta». Diario Página 12, 17/11/11.

PARA CITAR ESTE ARTÍCULO:

Rocca, M.V. (2018). "La reestatización de un servicio esencial en el área metropolitana de Buenos Aires. El caso de la empresa Agua y Saneamientos Argentinos S.A. (AYSA) (2006-2018)", DAAPGE, año 18, № 31 (jul-dic), 2018, pp. 111-146. Santa Fe, Argentina: UNL. 